\title{
Haptic Feedback in Teleoperation in Micro- and Nano-worlds
}

Aude Bolopion ${ }^{*, 1}$, Guillaume Millet ${ }^{*, 2}$, Cécile Pacoret ${ }^{*}, 3$ \& Stéphane Régnier ${ }^{3}$

*A. Bolopion, G. Millet, and C. Pacoret equally contributed to this work.

${ }^{1}$ A. Bolopion is with the Institut FEMTO-ST (Franche-Comté Électronique Mécanique Thermique et Optique - Sciences et Technologies), CNRS UMR 6174, 24 rue Alain Savary, 25000 Besançon, France. aude.bolopion@femto-st.fr

${ }^{2}$ G. Millet is with the Department of Computer Science, University of British Columbia, 2366 Main Mall, Vancouver, B.C.V6T1Z4, Canada.gmillet@cs.ubc.ca

${ }^{3}$ C. Pacoret and S. Régnier are with the Institut des Systèmes Intelligents et de Robotique, Université Pierre et Marie Curie, Paris 6, CNRS UMR 7222, 4 Place Jussieu, 75005 Paris, France. pacoret@isir.upmc.fr, $\underline{\text { regnier@isir.upmc.fr }}$ 


\begin{abstract}
Robotic systems have been developed to handle very small objects, but their use remains complex and necessitates long-duration training. Simulators, such as molecular simulators, can provide access to large amounts of raw data, but only highly trained users can interpret the results of such systems. Haptic feedback in teleoperation, which provides force-feedback to an operator, appears to be a promising solution for interaction with such systems, as it allows intuitiveness and flexibility. However several issues arise while implementing teleoperation schemes at the micro-nanoscale, owing to complex force-fields that must be transmitted to users, and scaling differences between the haptic device and the manipulated objects. Major advances in such technology have been made in recent years. This chapter reviews the main systems in this area and highlights how some fundamental issues in teleoperation for micro- and nano-scale applications have been addressed. The chapter considers three types of teleoperation, including: (1) direct (manipulation of real objects); (2) virtual (use of simulators); and (3) augmented (combining real robotic systems and simulators). Remaining issues that must be addressed for further advances in teleoperation for micro-nanoworlds are also discussed, including: (1) comprehension of phenomena that dictate very small object ( $<500$ micrometers) behavior; and (2) design of intuitive 3-D manipulation systems. Design guidelines to realize an intuitive haptic feedback teleoperation system at the micro-nanoscale level are proposed.
\end{abstract}

Keywords: Teleoperation, haptics, micromanipulation, nanomanipulation, molecular simulation, user testing. 
Micro-nanomanipulation is the manipulation of objects ranging from $1 \mathrm{~mm}$ down to $1 \mathrm{~nm}$. The primary challenge for this type of manipulation is facilitating user interaction with an intangible world. This challenge has often been approached through the use of simulations (see Figure 1). In order to facilitate performance in such applications, new methods must be developed for user understanding of the physical mechanisms that dictate behavior of very small objects, including artificial or biological microscopic objects. Furthermore, users must be provided with intuitive interfaces to facilitate, for example, micro-nanoassembly operations (i.e., assembly of components ranging from $1 \mathrm{~nm}$ to $1 \mathrm{~mm}$ ). To overcome these challenges, there is a need for teleoperation systems that enable the manipulation of objects in 3-D, while providing feedback on object interaction forces in real-time. This chapter proposes design guidelines for such systems.
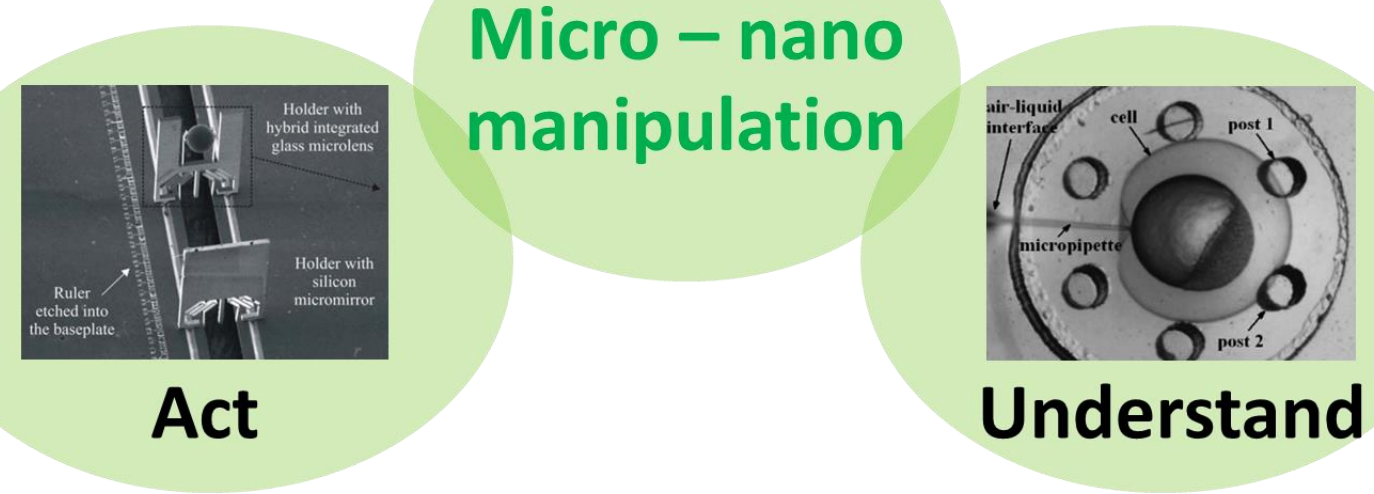

Figure 1. Micro-nano teleoperation systems must enable interaction with an intangible world. Users must be provided with knowledge about phenomena at this scale and intuitive interfaces 
for object manipulation. Photos in figure come from Liu, Sun, Wang, and Lansdorp (2007) and Bargiel, Rabenorosoa, Clévy, Gorecki, and Lutz (2010).

At the micro-nano scale, manual interaction with objects is impossible, owing to very small physical size of objects, as well as the fragility of the objects and tools, the complexity of force-fields among objects and high sensitivity of the overall system to environmental conditions. One solution to such applications is automated task performance. Related to this, some supporting results have been obtained, including high throughput of accurate automated positioning of objects with a size of hundreds of micrometers (Tamadazte, Le Fort-Piat, \& Marchand, 2011). Such systems fit the needs of repeated tasks on large numbers of objects. However, operator knowledge is not exploited, users cannot interact with objects while the automated task is being performed, and they typically do not receive feedback from the system in order to learn about objects or how the manipulation is occurring.

The use of automated assistance in user-directed manipulation appears as a promising alternative, which benefits from the interactivity of manual manipulation, while exploiting automated functions. Teleoperation with haptic feedback, which enables users to manipulate objects from a remote location while receiving force feedback, is one solution to transmit information intuitively to operators (Ferreira \& Mavroidis, 2006). ${ }^{1}$ In order to justify this alternative to nano-manipulation, teleoperation systems must support, for example, effective user control of robotic systems in assembly tasks, creation of innovative nanoelectromechanical systems, as well as design of molecular structures with dedicated properties or specific types of alloys. In some cases, teleoperation control may be integrated with virtual or synthetic environments for design tasks.

For such applications, three types of teleoperation can be identified (also see Figure 2):

\footnotetext{
${ }^{1}$ Haptic feedback is composed of both force and tactile feedback. However, only force feedback is commonly used on the micro-nanoscale. In the following, and unless stated otherwise, haptic feedback represents force feedback only.
} 
- Direct teleoperation: Operators use a haptic interface to control a robotic system that can handle micro-nano objects. Objects are commonly larger than $500 \mathrm{~nm}$ since most of the current robotic systems are not able to manipulate smaller individual objects. Interaction forces are, at most, a few micronewtons. These teleoperation systems aim to perform micro-nanoasssembly. The computation of haptic feedback is commonly based on the output of force, or position sensors;

- Virtual teleoperation: Users manipulate a virtual object in a virtual scene. The main applications are education, training and conceptual design of new systems. Education consists of teaching students basic concepts of force fields on the micro-nanoscale. In the case of training, virtual teleoperation provides experienced users with a tool to test new manipulation strategies. The main advantage of this type of control, compared to direct teleoperation, is that it avoids repeatability issues, owing to the high sensitivity of systems to environmental conditions, such as temperature and humidity. Virtual teleoperation also enables the conceptual design of new structures, such as new molecules in medicine production processes. This type of task is similar to the use of computer-aided design software for macroscale objects. ${ }^{2}$ However, the molecular structure design focuses on objects of a few nanometers to hundreds of micrometers, and interaction forces of a few nanonewtons;

- Augmented teleoperation: As in direct teleoperation, users manipulate real objects with a robotic system. Since the available feedback in direct teleoperation is limited by the number of sensors, augmented teleoperation uses simulation software based on a model of the task environment, to provide users with additional information, transmitted either haptically or visually.

\footnotetext{
${ }^{2}$ Macroscale corresponds to objects larger than $1 \mathrm{~mm}$.
} 


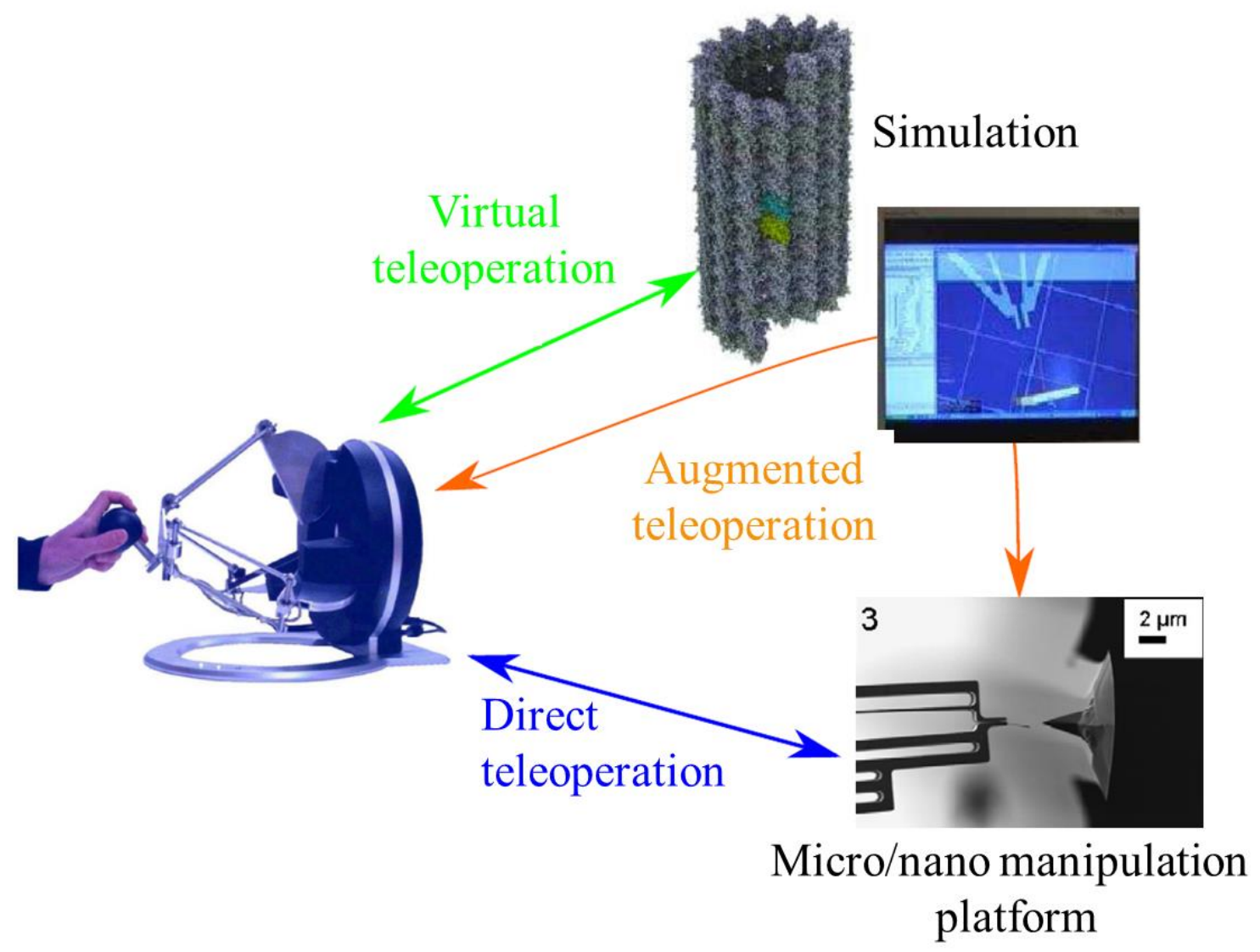

Figure 2. The three types of teleoperation: direct (the operator manipulates a haptic interface to control real objects); virtual (the operator controls virtual objects); and augmented (a real object is manipulated and additional feedback is provided based on a virtual scene). The image of the molecule comes from the SAMSON software (Grudinin \& Redon, 2010). SAMSON is a software platform for modeling and simulation of nanosystems (SAMSON stands for Software for Adaptive Modeling and Simulation of Nanosystems). It was developed by the NANO-D group at INRIA (French National Institute for Research in Computer Science and Control). The image of the gripper is reprinted with permission from Elsevier from Andersen et al. (2008) pp. 1128-1130. 
The structure of a teleoperation system for micro-nanoscale applications is similar for the three types of teleoperation. The user controls the position of a haptic interface/control $\left(X_{h}\right.$; see Figure 3). This position is used to set the position of the manipulated object $\left(X_{e}\right)$. The interaction force $\left(F_{e}\right)$, applied to the object, is measured or computed. This force is also used to compute the haptic force $\left(F_{h}\right)$ sent to the operator. As part of this coupling, control positions in the macroworld are scaled-down for inputs in the microworld. Conversely, the interaction forces in the microworld (commonly on the order of nano- or micro-newtons) are scaled-up or increased for presentation as haptic forces (on the order of newtons) at the control interface. ${ }^{3}$ This coupling must be highly transparent to the user (i.e., the haptic forces must be reliably transmitted to the operator through the haptic device) to accurately represent the interactions measured in the microworld, including complex force fields. ${ }^{4}$ Stability must also be ensured despite the scaling difference between the macroworld (the operator) and the microworld (the objects) that tend to induce instabilities.

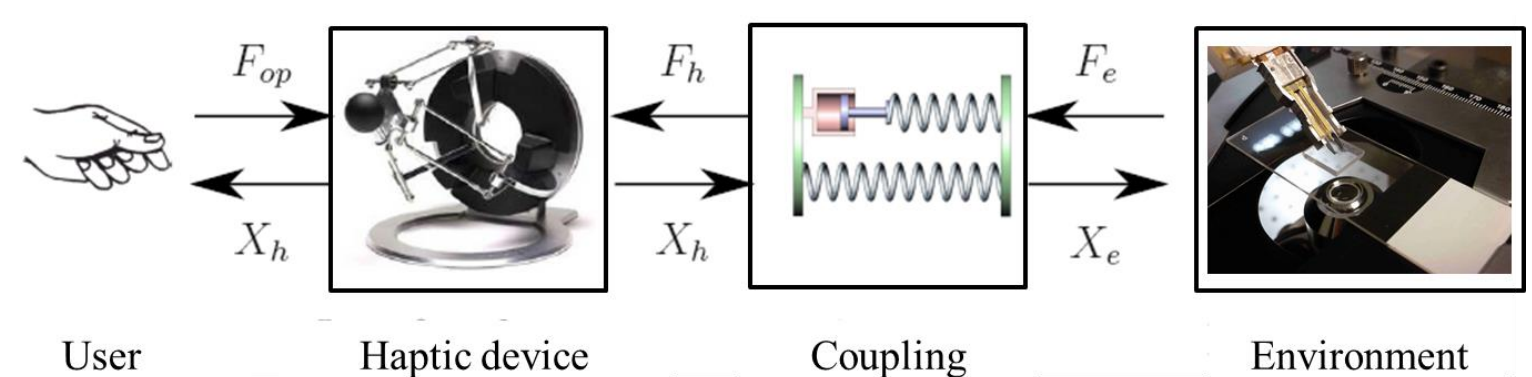

Figure 3. Structure of a teleoperation system. The user controls the position of the object in the environment with a haptic device through the coupling. A haptic force $\left(F_{h}\right)$ is provided.

In addition to classical teleoperation issues, such as transparency and stability, haptic feedback teleoperation systems for micro-nanoscale applications face challenges related to: (1) the low magnitude of the forces that must be transmitted; (2) the difficulty of measuring

\footnotetext{
${ }^{3}$ The coupling schemes allow the robot in the microworld to connect to the haptic device in the macroworld. They are represented in the block diagram formalism.

${ }^{4}$ A haptic device is a joystick or other control interface that can transmit forces.
} 
these forces; and (3) the fast dynamics of object states. In order to develop multi-purpose remote micro-nano handling systems, all these challenges must be addressed through effective system design. In the following sections, we review the main teleoperation systems that have been developed with haptic feedback for applications on the micro-nanoscale. Solutions to the aforementioned challenges are highlighted and design guidelines for future systems are established, based on researcher experiences with the different existing systems.

The remainder of the chapter is organized as follows. Section 0 presents existing direct teleoperation systems, as well as challenges that must be overcome and proposed solutions. Virtual teleoperation systems are presented in Section 0, and augmented teleoperation systems are described in Section 0. Evaluations of haptic teleoperation systems are presented in Section 0. Section 0 concludes the chapter and provides design guidelines for micro- and nano-teleoperated systems. Perspectives on haptic feedback teleoperation at the micronanoscale are highlighted.

\section{DIRECT TELEOPERATION}

To manipulate artificial or biological microscopic objects, specific robotized manipulation platforms have been developed. The size of the objects considered here is between $500 \mathrm{~nm}$ and $500 \mu \mathrm{m}$, and they are mostly spherical or cylindrical. The tasks typically performed with direct teleoperation are relatively basic and include, pushing and rolling, or indentation. Some pick-and-place operations can also be realized. Due to the specific properties of the microscale, specific strategies have been developed to perform these manipulations. The two main techniques are contact or non-contact manipulation. Contact manipulation consists of moving objects using miniaturized versions of classical tools, such as tips or microgrippers. In non-contact manipulation, objects are manipulated using remote force fields emitted from electrical or magnetic sources. The strategies pose two issues for associated haptic feedback 
to users, including: the forces that must be transmitted are, at most, a few micronewtons; and, on the microscale, the integration of force sensors into a manipulation platform is complex, and often not possible (Ni, Bolopion, Agnus, Benosman, \& Régnier, 2012). Below, we describe haptic feedback for both contact and non-contact manipulation.

\section{Contact manipulation}

Contact manipulation is the classical mode of manipulation in which a tool, often directly inspired from macro tools, is used. Several tools can be considered, but the most common ones are AFM (Atomic Force Microscope) cantilevers and microgrippers. ${ }^{5}$

Teleoperation using an AFM: The first use of teleoperation systems for micro- and nanoscale applications was recorded by Hatamura and Morishita (1990). The goal was to develop a system that was capable of scaling down the movements of an operator to control a micromanipulator. The system was also intended to reproduce phenomena occurring at the microscale, through visual and haptic feedback. However, this first implementation only provided visual feedback, and information about forces was presented visually; not haptically. The first teleoperation system with haptic feedback appeared in Hollis, Salcudean, and Abraham (1990). A haptic device was linked to a scanning tunneling microscope. Users control the in-plane displacement of the tip of the microscope. Vertical movement of the handle of the haptic device followed the vertical movements of the tip, so that users could 'feel' the topology of a substrate. However, substantial noise and hysteresis in the system limited the possible applications.

\footnotetext{
${ }^{5}$ AFM cantilevers are a few hundred micrometers long, a dozen micrometers wide, and a few micrometers thick. They may also have a tip at their extremity. Several systems are available to measure tool deformations. Since tool stiffness can be calibrated, the force applied can be computed.
} 
The first teleoperation with haptic feedback using an AFM was presented by Sitti and Hashimoto (1998). AFMs are commonly used tools for moving micron-sized objects. These tools only provide one degree-of-freedom (DOF) for control. Users control the in-plane position of the tool tip using a mouse (see Figure 4). Users can feel the repulsive forces when a force is applied on the substrate by the tip, as well as attractive forces when the tip is lifted away from the substrate (Sitti \& Hashimoto, 2003). Simple manipulation tasks were performed by Venture, Haliyo, Micaelli, and Régnier (2006) with an AFM setup, like that presented by Sitti and Hashimoto (2003). In particular, tasks of picking spheres by adhesion and releasing them by rolling were realized. Only vertical forces were transmitted to users. The use of a piezoresistive sensor limited the resolution of the measured force.
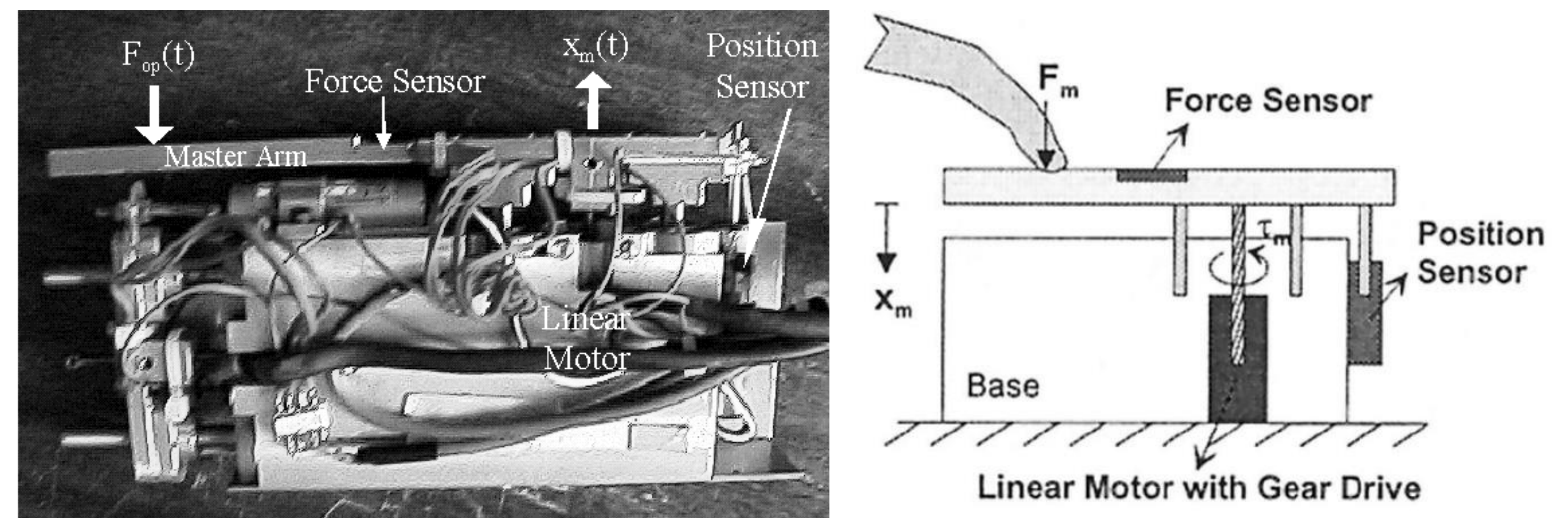

Figure 4. Haptic devices. Left: One-degree-of-freedom haptic device, enabling users to feel the topology of substrates. Copyright 1998 by IEEE. Reprinted, with permission, from Sitti and Hashimoto (1998b), pp. 1739-1746. Right: Schematic representation of the haptic device. Copyright 2003 by IEEE. Reprinted, with permission, from Sitti and Hashimoto (2003), pp. 287-298.

There are two reasons for the limitations of force direction and resolution in these systems. First, there is delay in the force measurement due to the data acquisition process. This delay produces vibrations in the haptic feedback. Second, there may be incomplete force measurement. Using an AFM, only two measurements (bending and torsion of the cantilever) 
are available. The haptic feedback is thus limited, since only the vertical force applied on the tip can be computed directly.

The first problem concerning oscillations in feedback and potential system instability must be addressed through analysis of control device and manipulator coupling schemes, particularly the influence of scaling factors (Sitti \& Hashimoto, 1998; Sitti \& Hashimoto, 2003). Indeed a force scaling factor (between $10^{6}$ to $10^{9}$ ) must be used to enhance measured forces at microscopic objects for transmission to the user. In addition, a displacement scaling factor $\left(10^{3}\right.$ to $\left.10^{6}\right)$ must be used to decrease the displacement of the haptic interface to direct the displacement of the micromanipulation tool. These scaling factors cause instabilities in the system operation. Solutions proposed for macro-sized systems have included that by Venture, Haliyo, Micaelli, and Régnier (2006), where the Llewelyn criterion was applied. ${ }^{6}$ However, such solutions proposed for macro-sized systems may not be adapted to the properties of a microworld. Kim and Sitti (2006) presented an adapted passivity controller that enabled users to feel attractive forces. It was first tested through simulation, and Onal and Sitti (2009) demonstrated its application to a real system. The stability of the system, despite control delays and modeling uncertainties, was examined by Boukhnifer and Ferreira (2006) and Boukhnifer and Ferreira (2007). They subsequently proposed a wave variable controller and a $\mathrm{H}_{\infty}$ controller to ensure stability. However, these techniques did not address the influence of scaling factors between the micro and the macro worlds. This issue was subsequently analyzed by several of us with others (Bolopion, Cagneau, Haliyo, \& Régnier, 2009). We addressed both stability and transparency issues in the system in order to achieve an effective haptic coupling for micro-nanoscale applications. To ensure stability, the ratio between the

\footnotetext{
${ }^{6}$ The criteria and controllers presented in this paragraph (the Llewelyn criterion, the passivity, wave variable, and $\mathrm{H}_{\infty}$ controllers) ensure that the system remains stable. Readers interested in more details about the control theory should refer to the identified references.
} 
force scaling factor and the displacement scaling factor was limited by the stiffness of the contact (between the tool tip and object).

The second issue limiting the type and resolution of force-feedback concerns the reconstruction of haptic forces, despite the lack of force measurement available from AFM tools (Zhang, Li, \& Xi, 2005). Since forces are computed from the measurement of the cantilever's deformations, as previously mentioned, only two measures are available: the vertical bending and the torsion. To improve the haptic feedback (Liu et al., 2006) analyzed the relation between the 3-D force applied to the cantilever and the measure of deformations, by taking into account the direction of cantilever movement. However, this technique is very sensitive to noise measurement and numerical errors during the computation of the force. Another approach was proposed by Onal and Sitti (2010), who used a model of friction between the atomic tool tip and the substrate. The topology of the substrate is assumed to be known; for example, from previous AFM scans. This solution is promising for providing users with information about the substrate, but it cannot be used for manipulations as the interaction force between the object and the tool cannot be determined.

Instead of transmitting haptic forces that perfectly match measured forces, it is possible to simply define haptic forces that will help users perform a given task. Such virtual force fields are called 'virtual guides'. A first approach to haptic-based model-oriented teleoperation was proposed in Shirinov, Kamenik and Fatikow (2004), where measurements from a piezoresistive cantilever were used to derive haptic feedback. Two main models were proposed, including free space and rigid wall models; however, no detailed models have been developed for complex manipulations. Virtual guides have been demonstrated for microscopic object rolling tasks (Bolopion, Cagneau, \& Régnier, 2009) in which 2-D haptic feedback has been provided to assist users in maintaining a tool on the middle line of a sphere during rolling. 
Teleoperation and microassembly: Following the work done on AFM based manipulation, a haptic AFM-based tweezer system was proposed, which integrated two AFM cantilevers with protruding tips (Xie \& Régnier, 2011). To detect the position of objects, the cantilevers were excited at their resonant frequency and the amplitude of oscillations was measured. When in contact with an object, the amplitude of oscillation decreases. Bolopion, Xie, Haliyo, and Régnier (2012) proposed an adapted haptic feedback system based on the measure of these oscillations. Virtual guides were implemented to assist the user in aligning the cantilevers to an object surface and closing the gripper (see Figure 5). Three-dimensional pick-and-place experiments with microspheres (diameter: 4-6 $\mu \mathrm{m}$ ) were also conducted in order to validate the approach.

Instead of an AFM cantilever, other tools, such as tuning forks, could be used. Tuning forks are quartz resonators onto which a sharp tip is glued. The force applied to the tip is calculated based on the measure of the frequency shift of the oscillations. Compared to AFM tools, tuning forks present a lower force resolution and are less sensitive to thermal noise. In addition, tuning forks are self-actuated (there is no need for an additional piezoelectric module to produce oscillations in the tool) and they are self-sensing (there is no need for a laser and photodiode to measure tool deformations, as with an AFM cantilever). The haptic detection of nanospheres, using one tuning fork, has been demonstrated by Niguès et al. (2012). 


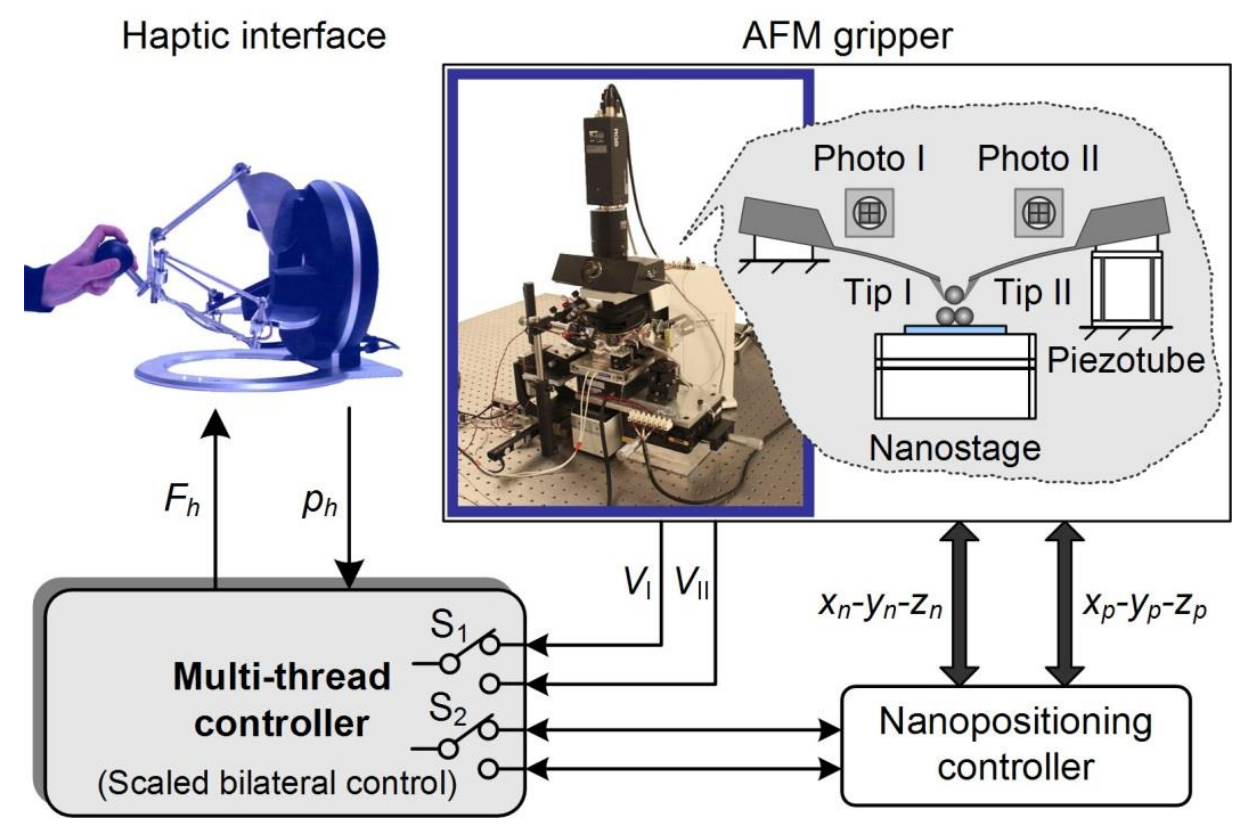

Figure 5. Two AFM cantilevers are used as a gripper. The operator controls the two tips (switch $S_{1}$ and $S_{2}$ ) sequentially, using the haptic device to position them with respect to an object. The nano "stage" is then used for the pick-and-place operation. The haptic feedback $F_{h}$ is based on the measurement of the variation of the cantilever oscillations Reprinted, with permission, from Bolopion, Xie, Haliyo, and Régnier (2012), pp. 116-127.Copyright 2012 by IEEE.

The previous approach of using two independent AFM cantilevers to form a gripper necessitated aligning each tool tip separately. This process is time-consuming and cannot be performed by novice users. Classical grippers are more adapted to pick-and-place tasks. However, haptic feedback of gripping force is necessary to prevent users from applying large forces that could damage objects and/or a tool (Kim D.-H., Kim, Kim, \& Cha, 2001). Grip force can be measured by a force sensor integrated in a manipulator, such as a piezoelectric polymer (e.g., Polyvinylidene Fluoride (PVDF)) film (Kim D.-H., Kim, Kang, \& Ju, 2003), or 
a piezoresistive sensor (Fahlbusch, Shirinov, \& Fatikow, 2002). In addition to the gripping force, haptic feedback can be used to assist users while aligning a gripper with an object. This approach has been validated on pick-and-place experiments with $45 \mu \mathrm{m}$ polystyrol microspheres (Schmid, Yechangunja, Thalhammer, \& Srinivasan, 2012).

Unfortunately, the integration of sensors in micro-nanoscale manipulators increases the complexity of the design and of the fabrication process of the gripper. Thus, many of the grippers that enable the manipulation of objects of less than $100 \mu \mathrm{m}$ are sensor-deprived. Consequently, haptic feedback force must be calculated using other information, such as the input voltage used to control the opening and closing of the gripper (Vijayasai et al., 2010). In this case, a calibration process is needed, where an object is grasped under a microscope. The instant at which grasping is determined by visual inspection, the corresponding system voltage should be recorded. During the manipulation process, a haptic force is sent to the user if the voltage input is higher than the predetermined voltage. However, there is no sensor feedback: the haptic force is based on the input signal, not on any sensor output. Furthermore, the calibration process must be performed for each type of object to be manipulated.

To overcome the issue of a lack of force sensing at micro-manipulators, vision is commonly used as a solution for detecting tool-object contact. Unfortunately, the update rate of frame-based acquisition processes of current cameras cannot ensure stable haptic feedback at the microscale level (e.g., low inertia of objects produces highly dynamic forces that cannot be revealed by classical cameras). The combination of a conventional frame-based camera with an asynchronous Address Event Representation (AER) silicon retina can overcome this issue (Ni, Bolopion, Agnus, Benosman, \& Régnier, 2012). Unlike frame-based cameras, artificial retinas transmit output as a continuous stream of asynchronous temporal events, in a manner similar to the output of cells of a biological retina. The reduction of redundant information enables high update rates. The asynchronous silicon retina can provide feedback 
on highly dynamic phenomena, whereas the frame-based camera retrieves the position of immobile objects. This approach has been validated through a pick-and-place experiment with spheres of $50 \mu \mathrm{m}$, using a piezoelectric gripper and haptic feedback (Ni, Bolopion, Agnus, Benosman, \& Régnier, 2012).

Teleoperation for biological applications: Cell manipulation is of great interest, particularly for intracytoplasmic cell injection, DNA injection and gene therapy. These manipulations are usually carried out manually by operators, based on visual feedback. However, such operators require intensive training and there is often a low success rate and poor repeatability for training protocols (Kim D.-H., Kim, Yun, \& Kwon, 2004). Some research has proposed using haptic feedback to reduce the force applied to a cell and thus increase the survival rate of the cell (see Figure 6). Force feedback also provides operators with a better understanding of the structure of the cell by reflecting its stiffness.

To transmit haptic feedback, it is necessary to measure the force applied at the cell. Force sensors based on a PVDF piezoelectric polymer film are commonly used, as they provide good sensitivity and a high signal-to-noise ratio (Cho \& Shim, 2004). A calibration phase is needed to obtain the value of the force applied at the cell, based on a measure of the voltage output of the sensor. Based on this force measurement, a haptic force is transmitted. This enables users to feel the force that is necessary to puncture the cell membrane. For example, Kim D.-H., Kim, Yun, and Kwon (2004) identified the force that must be applied to perform zebra fish egg-cell injection. The force needed to puncture the yolk membrane of the cell was three times that needed to puncture the chorion envelop. Haptic feedback also enabled users to compare the force that must be exerted depending on the cell type. A higher force must be applied to puncture salmon fish eggs compared to flying fish eggs (Pillarisetti, 
Anjum, Desai, Friedman, \& Brooks, 2005). Operators can thus get a deeper understanding of the cell structures.

User-based tests were performed by Pillarisetti, Pekarev, Brooks, and Desai (2007) to validate the use of haptic feedback for such cellular applications. Forty people were asked to inject trepan blue in zebra fish egg cells and to judge the success or failure of the operation (Figure 6). They were provided either with visual feedback only, or visual and force feedback. There was no difference in the completion time of the task. However, the outcome of the cell injection with combined visual and haptic feedback was superior to vision alone for all subjects. The haptic assistance was found to improve the overall efficiency of cell injection.
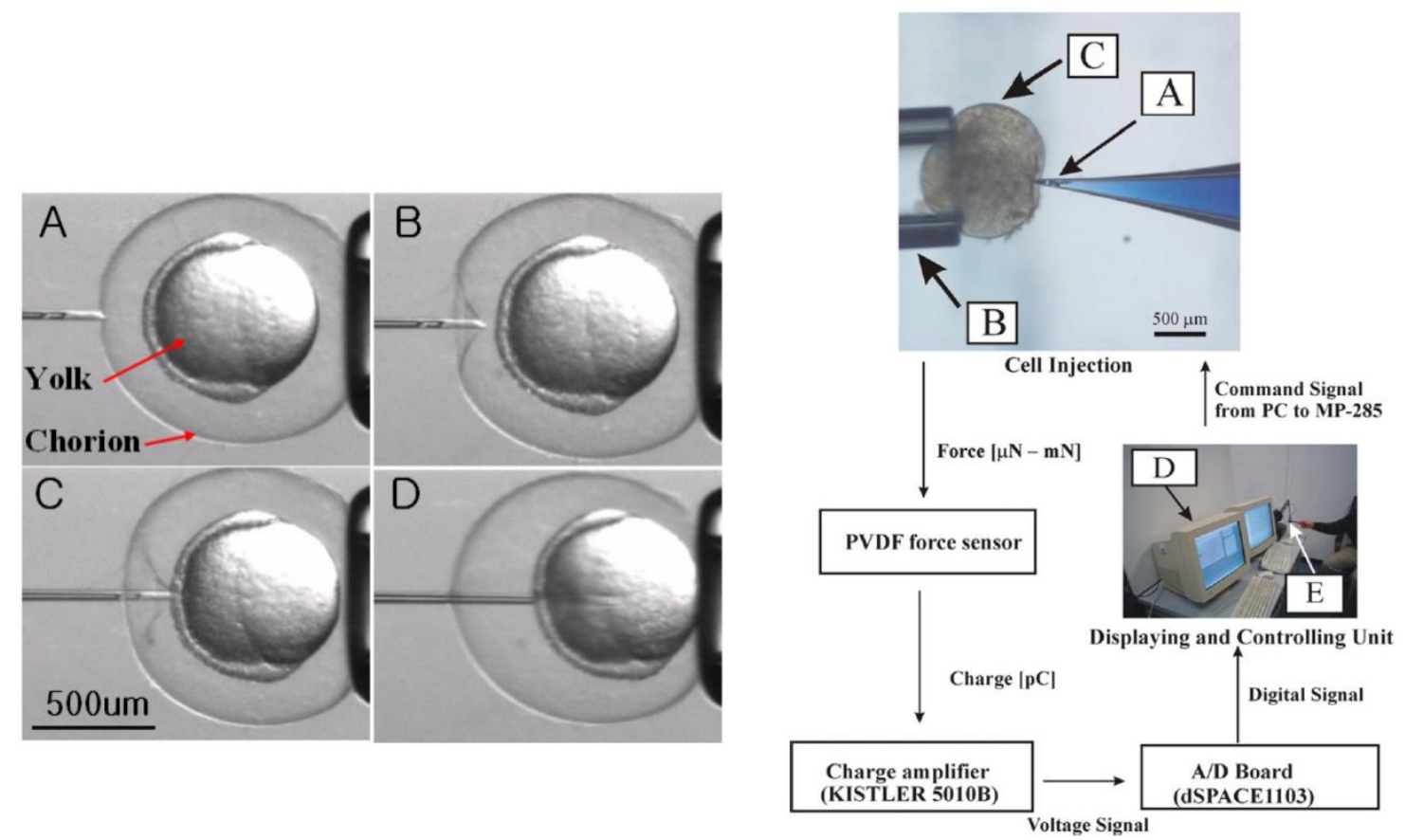

Plate (a): A: the glass pipette controlled by a Plate (b): Injection of a cell under visual and 3-DOF manipulator approaches the chorion; haptic feedback. The haptic force is B: pipette enters chorion; $\mathrm{C}$ : pipette contacts computed based on measurements by a outer membrane of yolk; and D: pipette PVDF force sensor (Pillarisetti, Pekarev, penetrates nucleus membrane (Kim D.-H., Brooks, \& Desai, 2007). 
Kim, Yun, \& Kwon, 2004).

Figure 6. Injection of zebra fish egg cell using robotic teleoperation systems. Copyright 2004 by IEEE. Reprinted, with permission, from Kim, Kim, Yun, and Kwon (2004), pp. $2412-$ 2417. Copyright 2007 by IEEE. Reprinted, with permission, from Pillarisetti, Pekarev, Brooks, and Desai (2007), pp. 322-331.

\section{Summary on haptic feedback for contact manipulation}

The first haptic feedback system for direct teleoperation in microworlds was developed less than 25 years ago. This system was the first to enable feeling of a microworld by presenting the topology of substrates or by transmitting interaction forces between two objects, haptically. Several studies have since been conducted on stability and transparency issues that arise in such systems, as well as on the computation of haptic feedback. These investigations have enabled major advances in the area. Haptic feedback has been implemented in complex systems to control different types of tools such as cantilevers, grippers or micropipettes. Current systems have proved to be beneficial for both micro-assembly of artificial objects and injection of biological cells.

Haptic feedback for direct teleoperation is now a mature field, and should be proposed for end users (Bolopion \& Régnier, 2013). Such feedback in control can be beneficial for operators who are designing new prototypes, such as biomedical or electronic devices, that require assembly of micron-sized parts.

Several developments can be foreseen to increase the efficiency of such systems; among them is the design of dedicated haptic interfaces to render highly dynamic forces and provide ergonomic hand controls (see Figure 7 for an example prototype). Tests of such designs must be performed with end users in order to define the exact needs of the budding micro-assembly industry. 


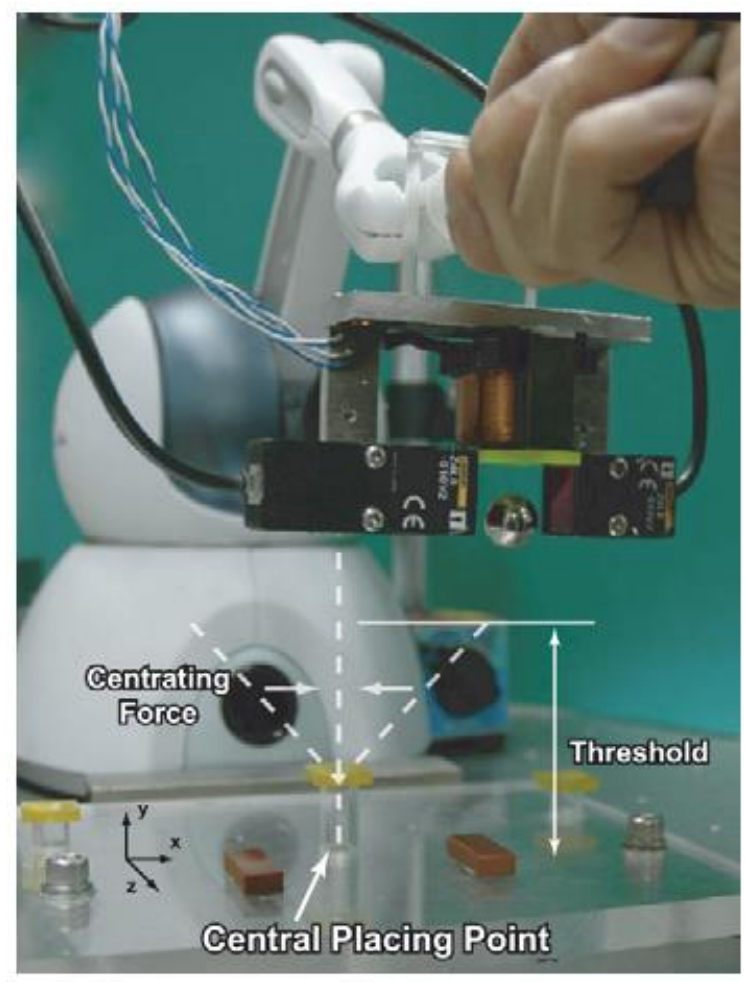

Figure 7. Magnetic haptic tweezer. Reprinted with permission from Elsevier from van West, Yamamoto, and Higuchi (2007), pp. 345-356.The handled object is a $\varnothing 12.7 \mathrm{~mm}$ iron ball.

\section{Non-contact manipulation}

Non-contact manipulation differs from contact manipulation since the actuation source used to manipulate objects is not a material tool but a field potential: magnetic, electromagnetic, electrophoresis or microfluidic field, for example. Individual object or group manipulations can be performed, but haptic teleoperation has only been developed for individual object manipulation.

The two main types of systems that have been developed with haptic feedback, include magnetic tweezers (Gosse \& Croquette, 2002; van West, Yamamoto, \& Higuchi, 2007) (see Figure 7) and optical tweezers (Ashkin, Dziedzic, Bjorkholm, \& Chu, 1986; Arai, Ogawa, \& Fukuda, 2000). Today, these systems are refined and widespread in application (Neuman \& Block, 2004; de Vries, Krenn, van Driel, \& Kanger, 2005). In general, an object is levitated in 
a magnetic field or a laser focus. The actuation consists of moving the magnetic or optical trap, which represents the minimum field potential. This displacement induces restoring forces which drag trapped objects along. The small gap between the trap and the object position provides information about movement forces. Related to this, the stiffness of this system has a linear domain. The actuation and force measurement are available in three dimensions under an optical microscope. Piconewtons can be measured for objects ranging in size from a few hundred micrometers to nanometers. Non-contact techniques like this avoid adhesion phenomena and friction, which may damage objects, but also limit highly dynamic forces that are difficult to control and to feed back to a user.

Advantages of non-contact manipulation: In the microscale dimension, field potential interactions are simpler to model than contact interactions. Additionally, levitated objects have negligible inertia compared to field-restoring forces. Pull-in or pull-off dynamic adhesion phenomena, which can have considerable impact on miniaturized tools for contact manipulation, are almost negligible in non-contact manipulation, given the size of particles being manipulated (see Figure 8). Consequently, the current position of objects and interaction forces are not dependent on prior system states (hysteresis), which is convenient for haptic teleoperation.

In addition, the properties of stiffness, mass and damping promote the stability of the couple between the user control device and field source. The stiffness is much smaller than in contact applications (Optical tweezers: $10^{-7}$ to $10^{-5} \mathrm{~N} / \mathrm{m}$ vs. AFM: $10^{-3}$ to $10^{2} \mathrm{~N} / \mathrm{m}$ ). The energy due to forces applied to objects is dissipated almost immediately, helping to stabilize the haptic feedback loop. Consequently, stable, direct haptic control can occur over a comfortable displacement range and with high levels of force feedback. The transparency of feedback is, consequently, very good for users. 


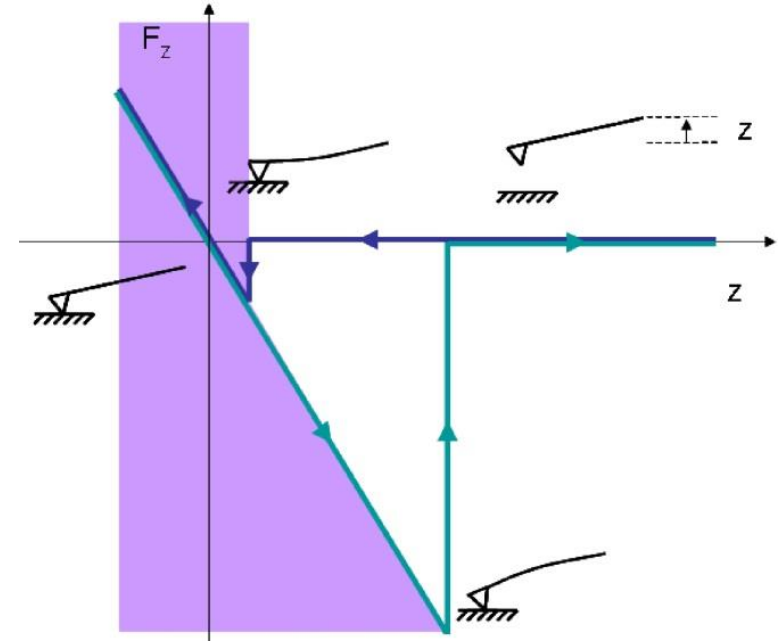

Plate (a): AFM (contact manipulation)

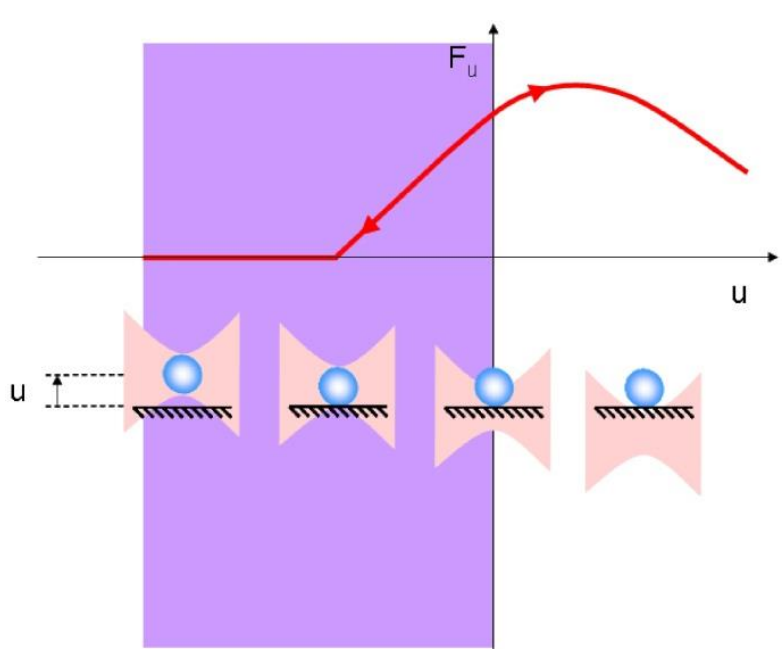

Plate (b): Optical tweezer (non-contact manipulation)

Figure 8. Comparison of approach-retract characteristic curves of contact and non-contact manipulation examples. The approach-retract test is used widely at the microscale to characterize interactions between two objects. Objects are first brought in close proximity (approach phase) and then in contact. The retract phase consists of separating the objects. This test highlights both the long-range attractive forces and the contact repulsive forces occurring at the microscale. Reprinted with permission from Pacoret and Régnier (2013). Copyright 2013 by AIP Publishing LLC.

Haptic optical tweezers: Teleoperative control is less developed for magnetic or electromagnetic tweezers than for laser trapping, even though the principle is fully transposable. This fact is based mainly on the greater flexibility of the laser-based technique: it is easier to implement and control laser traps. Therefore, only examples of optical haptic tweezers will be discussed in more detail. 
The first teleoperation of optical tweezers was presented by Arai, Ogawa, and Fukuda (2000). Force measurement was realized using a photodiode. The level of control was limited when manipulated objects approached obstacles. The force measurement using a photodiode was not robust with respect to perturbations.

Exploration of the surface of a cell was performed using teleoperated optical tweezers (Sugiura, Nakao, Sato, \& Minato, 2008). Haptic feedback was also used to transmit forces in manipulations of nanowires (Lee, Lee, \& Lee, 2007). In these studies, forces were estimated using images from cameras. However, such sensor systems are slow and induce limitations on the teleoperation systems (as described above for contact techniques).

Major research has also been conducted on virtual guides in non-contact systems, which can compensate for a lack of real-time force measurements. Obstacles are localized before a task is performed and the user is then assisted with haptic feedback for collision avoidance (Bukusoglu, Basdogan, Kiraz, \& Kurt, 2008). User evaluations have revealed the benefit of this approach.

Possible applications of such systems are typically limited by the available workspace, the low frequency of actuators, or the low frequency of force measurement devices. Existing optical tweezer platforms have not been developed for force-feedback teleoperation. (Existing systems have simulated forces.) A specific system with dedicated actuation and sensing components must be developed to elevate this technique to its full potential.

Specific design for haptic optical tweezers: Pacoret et al. (2009) proposed an optical tweezer system designed entirely for haptic feedback. The system provides a large workspace for actuation and measurement. A CMOS camera is used for $500 \mathrm{~Hz}$ force measurement and centroid image processing, giving fast and high resolution data. 
With regard to the coupling issue (control device to remote tool), since optical tweezers represent overdamped systems, experimental and model-based results have revealed good stability. As only scaling gains are required (force scaling factor: $A_{f}=10^{-12}$; displacement scaling factor: $A_{d}=10^{-3}$ ), the transparency of the system and characteristics of the task environment are excellent. Brownian motion is fed back to the user, as well as the viscous drag of the (aqueous) environment. Pacoret et al. (2009) conducted haptic exploration of a corner of a microelectromechanical system (MEMS) revealing clear sensations for users (see Figure 9).

The robustness of force measurement in this type of system is also an important feature for users, as the measurement supports direct force feedback via a haptic device. Related to this, environmental perturbations need to be taken into account, including: loss of image focus, obstacles, impurities, etc. With this in mind, a new camera technology was developed by Ni, Pacoret, Benosman, Ieng, and Régnier (2011) to address optical tweezer measurement requirements. They developed a dynamic vision sensor with asynchronous update of pixels in order to provide information on image intensity changes over time. Image processing was performed on a sparse matrix of pixels in a continuous flow up to $30 \mathrm{kHz}$. Depending upon experimental conditions, this algorithm can be very complex for ensuring robust sensing. 


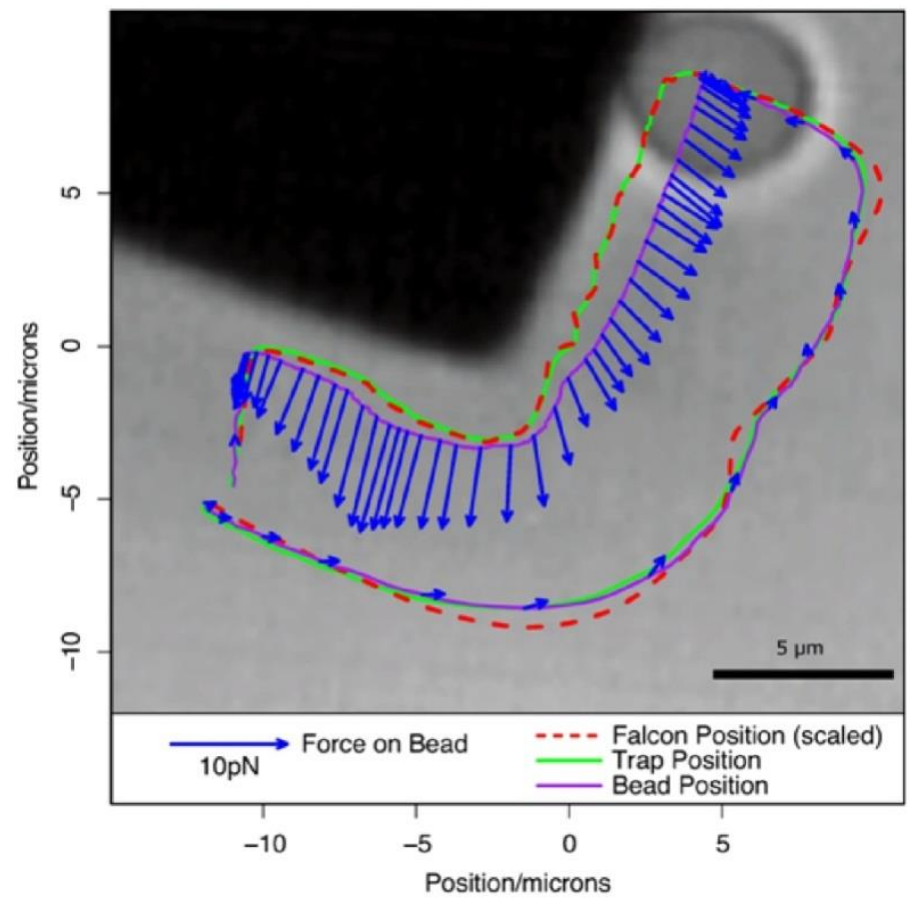

Figure 9. Exploration with a haptic optical tweezer of a $100 \mu \mathrm{m}$ silicon MEMS (Pacoret et al., 2009).

\section{Summary on haptic feedback for non-contact manipulation}

Optical tweezers offer many possibilities for the improvement of direct teleoperation for micro- to nano-scaled manipulation. The compatibility of such tweezers with biological samples (Bustamante, Bryant, \& Smith, 2003; Zhang \& Liu, 2008) allows us to think of stretching a cell or DNA with haptic feedback. Several promising future research directions can be identified, based on the above review:

- The ability of trapping multiple objects with a single laser by rapidly switching from one object to another may be efficient for performing high complexity micro-assembly (Rodrigo et al., 2009) with haptic feedback.

- The trapping of micro-tools with complex geometries can also be useful, as the technique can be used to induce rotation of objects through pushing motions (Ikin, Carberry, Gibson, Padgett, \& Miles, 2009). 
- Different investigations have been performed to measure forces on laser trapped objects (Ruh, B., \& Rohrbach, 2011), including vertical forces with cameras (Bowman, Preece, Gibson, \& Padgett, 2011). Such measurement systems support implementation of force-feedback teleoperation systems in mico-nanoscale applications, like cell manipulation (Bowman, Preece, Gibson, \& Padgett, 2011; Onda $\&$ Arai, 2012).

\section{VIRTUAL TELEOPERATION}

Virtual teleoperation systems are based on simulator use. Two main types of simulation software are available. The first one is based on macroscopic simulators, to which specific force fields are added. This software is used to represent operations done on micro-nano manipulation platforms. However, results are limited by the accuracy of simulated force fields. The second type of software is based on an atomic description of the system under study and simulates global behavior by adding the individual contributions of all atoms. Such applications are limited by simulation processing time as the size of the target molecular system increases. In general, the application of virtual teleoperation is primarily focused on molecular simulation and simulations are used to find new molecular properties, or for conceptual design of innovative structures. Another example is the use of simulation for conceptual design of new medicines and to test interaction force between two molecules.

Virtual environments can also be used for educational purposes, to teach students complex force fields at the microscale. In addition, they can be used by experts to test strategies of virtual object manipulation, new control gestures as they are enabled in a system, or for the conceptual design of new objects or biological entities.

\section{Teaching}


There is currently an emerging generation of engineers specializing in nanotechnology, whose training involves increasing familiarity with physical phenomena on the nanoscale. An interactive virtual reality tool may contribute to promoting awareness of the different aspects of nanoscale phenomena, by providing a dynamic and more complete representation. Haptic information in virtual reality can enhance user understanding by providing an alternate representation of objects as a basis for learning concepts on the nanoscale.

A growing research community is exploring the effectiveness of virtual reality simulations for the enhancement of student understanding of complex science topics (Murayama, Shimizu, Nam, Satoh, \& Sato, 2007; Sankaranarayanan, Weghorst, Sanner, Gillet, \& Olson, 2003; Sourina, Torres, \& Wang, 2008). Providing force-feedback to students with a homemade, low-cost 'haptic paddle', Okamura et al. (2002) showed that educational haptics are appropriate for teaching dynamic systems. In the context of nanoscience learning, some recent work has investigated the impact of virtual reality, mainly haptic augmentation, for teaching micro-nanoscale properties, such as virus morphology in biology (Jones, Minogue, Tretter, Negishi, \& Taylor, 2006), the approach-retract phenomenon in microscopy (Marchi et al., 2005), or protein-ligand docking in biomolecular chemistry (Persson et al., 2007). ${ }^{7}$

In addition to haptic feedback, graphical analogies can aid understanding. For instance, Marchi et al. (2005) presented the approach-retract interaction of an AFM cantilever with a microscopic object. They used an atomic representation. A triangular tool tip was applied to an elastic layer of atoms depicting a sample surface. A vertical line with no free length symbolized the cantilever. Another example is the graphical representation of potential variation in the approach-retract interaction phenomenon, which has been represented as a

\footnotetext{
${ }^{7}$ Test to characterize the interactions between two objects. These objects are first brought in close proximity (approach phase), then in contact, and finally they are separated (retract phase).
} 
ball rolling down into the gap of a field potential (Marliere, Urma, Florens, \& Marchi, 2004). Podolefsky and Finkelstein (2006) pointed out that such graphical analogies can be used to promote student learning in physics.

\section{Manipulation tasks}

Virtual teleoperation of an AFM: The first virtual teleoperation system that was developed for exploration using an AFM was presented by Grange, Conti, Helmer, Rouiller, and Baur (2001). A user can navigate a substrate that has been scanned using an AFM tip. In this system, only the geometry of the substrate is fed back to the user. A more complex simulator was used by Kim and Sitti (2006) to simulate indentation tasks. Interaction forces between the tool tip and the substrate are computed based on a Maugis-Dugdale model (Maugis, 2000). This latter simulator has also been used to test different coupling schemes, such as a passivity controller. These early simulations enabled only approach-retract or indentation tasks. In Vogl, Ma, and Sitti (2006), the geometry of a substrate was interpolated directly from real measurements, based on splines. Several system parameters could be tuned to change the representation of substrate physical properties, such as the Young modulus or the Poisson ratio. More realistic experiments can thus be performed with such a system.

Manipulation simulators have also been used to establish experimental protocols. In particular, path-planning with a simulator allows for decisions about adequate displacement of a tool for substrate exploration. The trajectory of the AFM tip can be defined to avoid obstacles. When the simulation is presented to users, virtual guides, as well as repulsive force fields, can be displayed haptically to assist the user in the task (Gao \& Lécuyer, 2009; Varol, Gunev, \& Basdogan, 2006). After an acceptable motion strategy has been defined for the virtual environment, it is possible to transpose the manipulation protocol to a real manipulation task with the AFM tip. This step has not yet been achieved. Different 
configurations of haptic feedback can also be tested to define the most appropriate strategy, depending on the task to be performed (Millet, Lécuyer, Burkhardt, Haliyo, \& Régnier, 2008).

Virtual teleoperation for molecular simulations: Molecular simulators are gaining attention as they can now be used to compute interactions between molecules of complex systems (Hamdi, Ferreira, Sharma, \& Mavroidis, 2008). However, it is necessary to propose an intuitive manipulation mode for users. Teleoperation with haptic feedback is a promising solution, and several systems have been proposed.

The first work to demonstrate interest in haptic interaction for molecular simulation was the GROPE project in 1990 (Ouh-Young, Pique, Hughes, Srinivasan, \& Brooks Jr., 1988; Brooks Jr., Ouh-Young, Batter, \& Kilpatrick, 1990); illustrated in Figure 10(a)). 


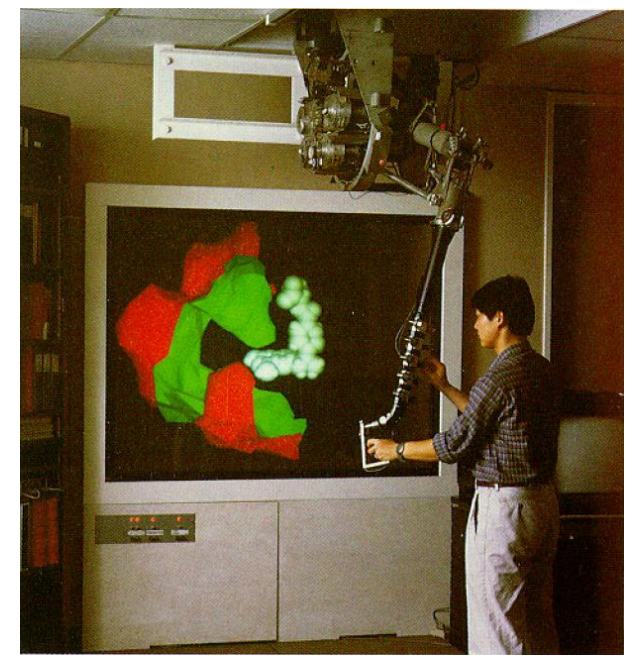

Plate (a): Molecular teleoperation system - GROPE project.

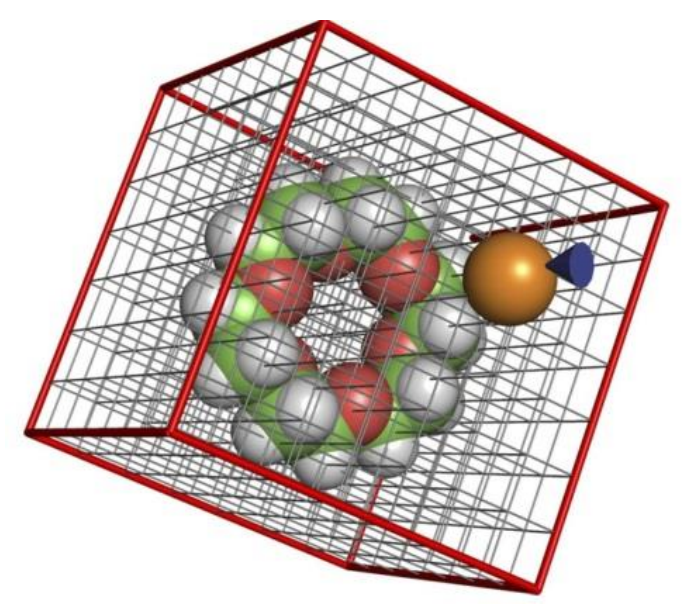

Plate (b): A pre-computed grid is used to determine molecular interactions in a short time and to ensure stable haptic feedback. Reprinted with permission from Elsevier from Wollacott, and Merz (2007), pp. 801805.

Figure 10. Haptic feedback teleoperation systems for molecular simulation.

To address the needs of biologists and pharmacologists in, for example, developing new medicines, complex virtual reality simulators have been developed. However, major stability problems arise in such applications, as a result of computational processing time and scaling differences between user control actions in the macroworld and object manipulations in the microworld. A trade-off must be found between the precision of the simulation and system stability. Several approaches have been proposed:

- Decreasing computation time: The most common solution is to pre-compute force grids offline in order to estimate force values during interaction (Figure $10 \mathrm{~b}$ ). This approach can be combined with making rigid those parts of molecules not being manipulated (Lai-Yuen \& Lee, 2006; Nagata, Mizushima, \& Tanaka, 2002; Wollacott 
\& Merz Jr., 2007). However, only approximate simulations can be presented as effect of molecular reconfiguration on force fields during simulation use cannot be taken into account. The molecular force fields used to compute the haptic feedback can also be simplified. In Lee and Lyons (2004), the repulsion between two atoms was modeled by stiffness. The precision of the simulation then decreased;

- Limitation of scaling factors: A trade-off among simulation stability, amplification of haptic feedback, and ease of user manipulation must be found (Wollacott \& Merz Jr., 2007). If force feedback is too low, the user will not benefit from the haptic modality. If force feedback is too great, it might lead to instability, and forces higher than the limit of the haptic interface will be truncated. Information on changes in force intensity above this limit will be lost. The displacement scaling factor should also be considered carefully, since a low value will lead to small molecular displacement, which can lead to time-consuming experiments. If the scaling factor is set too high, system instability can occur. A solution to this last issue is to combine both velocity and position control (Subasi \& Basdogan, 2008);

- Addition of damping to the simulation: Control damping increases system stability but decreases transparency of the real molecular environment to the user. Wave variables have also been proposed to promote stability, but they too decrease transparency (Daunay \& Régnier, 2009);

- Design of force control haptic coupling for molecular simulation: Instead of controlling the position of the molecule in a simulation, the user can apply a force to it. Such coupling is less sensitive to system instabilities and enables the user to intuitively apply deformations on molecular structures (Bolopion, Cagneau, Redon, \& Régnier, 2010). However, this manipulation mode might be less intuitive for moving molecules than the position mode; 
- Variable gain haptic coupling: Instead of being constant, the values of the force and displacement scaling factors used in the coupling can vary. For example, while being close to another molecule the displacement scaling factor might be greater in order to scale down the movement of the haptic device and enable greater precision. Similarly, the force scaling factor might amplify small attractive forces rather than large repulsive ones, so that they are both felt by the user without being truncated. Recent user testing has shown this approach to improve the trade-off between stability, ease of manipulation and quality of the force feedback in molecular simulations (Bolopion, Cagneau, Redon, \& Régnier, 2011). However, the system requires substantial training in order to be used by novice operators.

In most of the systems described above, only one manipulation mode is presented and either the position of the molecule or the force applied to it is controlled. This lack of diversity restrains the applications of such simulations. Only a few complex operations, such as the measurement of molecule stiffness, have been presented (Hamdi, Sharma, Ferreira, \& Mavroidis, 2005; Hamdi, Ferreira, Sharma, \& Mavroidis, 2008).

Virtual teleoperation for cell injection: Cell injection is another important application field for virtual teleoperation. Several simulators have been developed (Abe, Mizokami, Kinoshita, \& He, 2007), particularly for training on injection procedures (Le, Nahavandi, \& Creighton, 2010). Simulators are also used to test haptic feedback strategies before implementing cues in real manipulations, such as the haptic guidance approach presented by Ghanbari et al. (2010). They provided haptic feedback to assist users during the injection by ensuring that they performed the procedure at the desired cell location. They limited micropipette tip motion to a conical volume and prevented users from moving the pipette too far inside the cell. 
Simulators providing both visual and haptic feedback have also been proposed for cell injection (Ladjal, Hanus, \& Ferreira, 2011; Ladjal H. et al., 2012). These models include topological information on living cells (shape and dimensions) and representations of biological structure (cytoplasm layers, cytoskeletons and nuclei). This is combined with haptic feedback on forces at the cell during manipulation.

\section{Summary on virtual teleoperation}

Many virtual teleoperation systems have been proposed for microscale applications. They cover a large range of applications, from AFM-based manipulation to molecular simulation. The main limitation of these virtual environments is the simplicity of the models used for the simulation. At the macroscale the laws of physics that determine the behavior of objects are well known, and many simulators have been developed for industry, such as computer-aided design software. In contrast, models of the microscale are still uncertain and fail to accurately predict microscopic object behaviors obtained experimentally. Thus, the use of current virtual teleoperation systems is restricted to education and evaluation of the systems through user tests. There are also proof-of-concept systems that have been developed for training of technical gestures for system control in applications such as cell injection. These systems also facilitate testing of haptic coupling strategies (control device with virtual tools) in specific manipulation tasks.

Actual teleoperation systems coupled with molecular simulation software draw attention since they provide access to otherwise inaccessible interactions, which are key

elements in the development of new medicines. To drastically increase the potential applications of these virtual teleoperation systems, a major effort must be made to improve simulation models at the microscale. 


\section{AUGMENTED TELEOPERATION}

Direct teleoperation systems enable the manipulation of real objects. However, feedback is often limited to the output of existing sensor technology (force and/or vision). To enhance the immersion of a user in an application, additional feedback can be generated from a task/environment model and presented through visual or haptic channels. This is the purpose of augmented teleoperation, which enables the performance of tasks on real objects with the benefit of additional information through a simulated scene.

\section{Augmented Teleoperation}

Augmented teleoperation systems have been developed for AFM systems. The first system was composed of a haptic interface and a visualization unit, as illustrated in Figure 11 (Taylor II et al., 1997). The system supported semi-teleoperated manipulation in which the operator controlled the overall operation while some tasks were performed automatically (Falvo et al., 1999; Guthold et al., 2000). A 3-D representation of the microscale work environment was also presented.

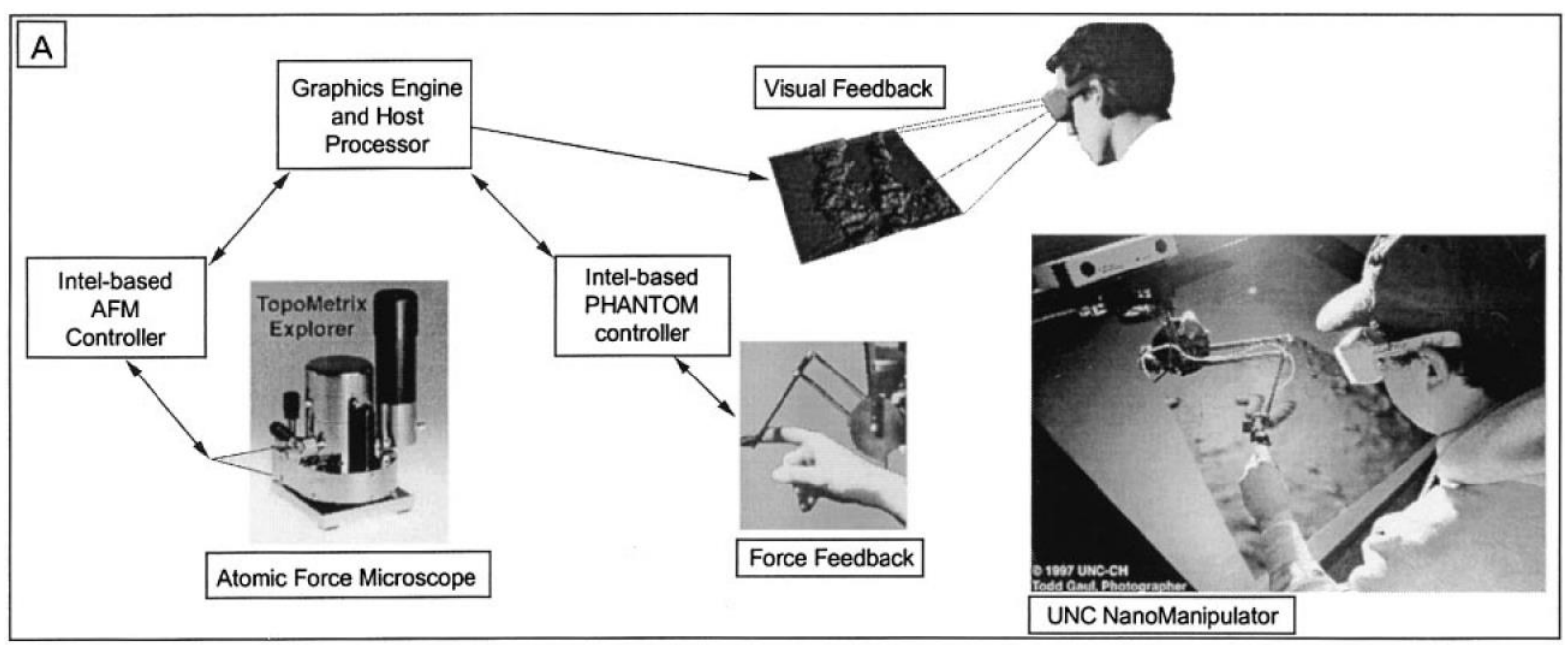

Figure 11. Set-up of an augmented reality micromanipulation platform. Reprinted with permission from Elsevier from Guthold et al. (1999). 
Most augmented teleoperation systems that have been developed integrate visual reconstruction of the task scene with added information, such as visualization of deformations applied to objects (see Figure 12; Fok, Liu, \& Li, 2005; Onal \& Sitti, 2009). This approach enables enhancement of small environment features that would not be visible to an optical microscope. The virtual reconstruction of the scene is usually based on a model of tool tip/substrate interactions, such as the Maugis-Dugdale model. As in virtual teleoperation, the fidelity of the simulation is a key issue for transmitting accurate information to the user.
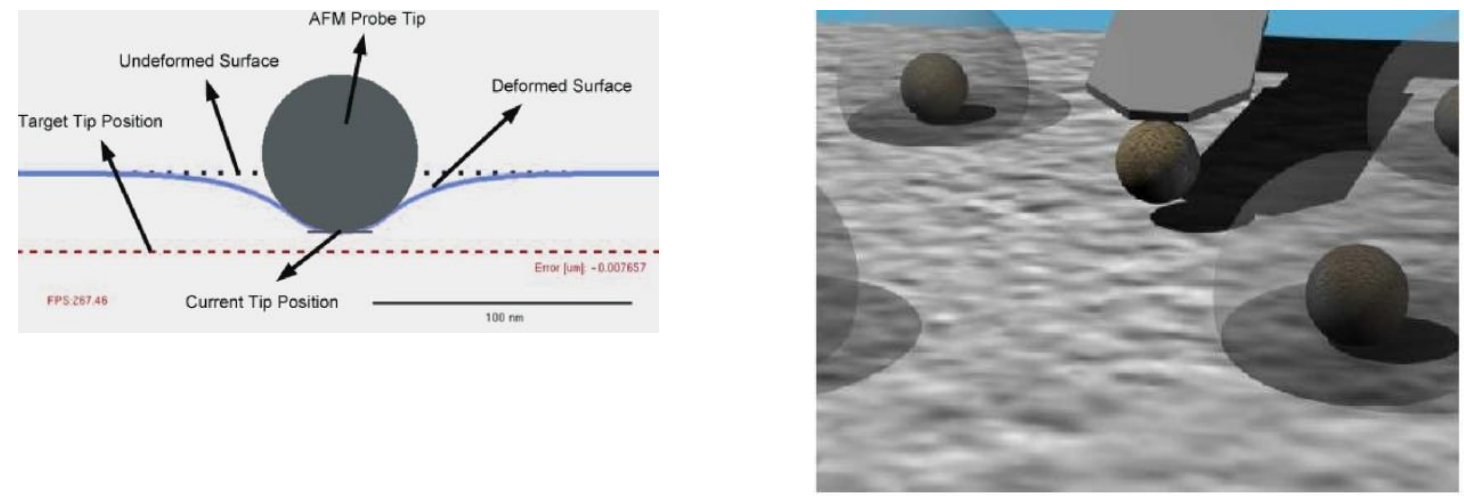

Plate (a): Visualization of mechanical Plate (b): Visual indication of virtual guides deformations of a substrate during approach- to indicate areas that should be avoided to retraction experiments (Onal \& Sitti, 2009). prevent objects from colliding with obstacles Reprinted, with permission, from Ammi and Ferreira (2007). Copyright 2007 by IEEE.

Figure 12. Augmented teleoperation systems: visual information is added to assist the user.

Visual virtual guides can also be added to the scene display. In Ammi and Ferreira (2007), the optimal path to perform a given task, as well as areas to be avoided to prevent collisions between a tool and objects, were simulated (see Figure 12, Plate (b)). This information was also rendered haptically. To ensure that the virtual scene was reconstructed 
with a high fidelity, the virtual display was based on a preliminary scan of the real substrate surface.

Augmented teleoperation can also be used to compensate for the slow image acquisition time of scanning electron microscopes (SEM) (Bolopion et al., 2011). In this case, a simplified 3-D virtual scene is presented to the user. The virtual scene is updated at a low rate during the manipulation process, based on images of the real scene, in order to avoid deviations or "drift" of the model from the real scene (due to poor registration). In addition, transmitting SEM images through the Internet network results in slow transmission rates that are not compatible with the stability of haptic feedback. One solution is to only transmit the position of objects and the tool in the scene, and to use this information to reconstruct the more complete virtual scene (Bolopion et al., 2012).

Augmented teleoperation systems are also used for biological applications, and more specifically for cell injection (Ammi, Ladjal, \& Ferreira, 2006). The haptic feedback provided is based on a mechanical model of the cell. The simulation can be updated, according to images coming from a microscope, to provide information about the deformation of the cell (Kim, Janabi-Sharifi, \& Kim, 2008).

\section{Summary on augmented teleoperation and assistance in teleoperation}

Most augmented teleoperation systems concentrate on haptic and visual feedback. In addition, audio displays can be used to enhance the immersion of a user. This topic has been widely studied for teleoperation on the macroscale, but only a few investigations have been conducted at the micro- and nano-scale. Preliminary work combining haptic and audio displays for AFM manipulation can be found in Marchi et al. (2005). However, there is still a lack of experimental validation on applications for complex tasks, as well as a lack of proper evaluation of any benefits based on user tests. 


\section{EVALUATION OF HAPTIC TELEOPERATION SYSTEMS}

The previous sections described the concepts of direct, virtual and augmented teleoperation for micro- and nano-scale applications. However, teleoperation, as a human-computer interaction, requires particular attention to the needs, wants and limitations of end users at each stage of the design process; that is, to employ user-centered design and usability testing.

In the framework of system acceptability (Nielsen, 1993), this implies evaluating the teleoperation systems not only for accuracy and robustness, but also for utility and usability. Usability of a teleoperation system represents the extent to which the system can be used by specified users, to achieve specified goals with effectiveness, efficiency and satisfaction in a specified context of use (ISO 9241-11, 1998).

Usability includes such quality attributes as:

- Learnability: how easy is it for users to accomplish basic tasks the first time?

- Memorability: when users return to the system after a period of not using it, how easily can they establish proficiency?

- Recoverability: how many errors do users make, how severe are those errors, and how easily can they recover from the errors?

- Efficiency: once users have learned the system, how quickly can they perform tasks?

- Satisfaction: how pleasant is it to use the system? (Dix et al., 2009)

In contrast to macroscale teleoperation, as we stated at the beginning of this chapter, micro-nanoscale teleoperation systems must enable interaction with an intangible world that is not directly sensed by users and, therefore, often unintuitive to these users. Simply put, most users are not familiar with the interaction phenomena that occur at such small scales. The 
selection of haptic forces, based on reliable rendering of interaction forces, or the use of virtual guides in a simulation interface, must be discussed and evaluated by users for usability. Other modalities, such as vision, should also be taken into account in such evaluations.

In this section, we present examples of user-based evaluations for both manipulation tasks in micro-nanoscale environments and education on physical phenomena in such environments. The benefit of haptic feedback at the micro-nanoscale is analyzed. Since current micro-nano-manipulation set-ups for real objects are very sensitive to environmental conditions and have poor repeatability, virtual teleoperation systems are primarily used for evaluation studies. Through the identified examples, we also assess the choice of feedback rendering methods (i.e., reliable transmission of actual interaction forces or the use of virtual guides).

\section{User-based evaluations of haptic aids for manipulation tasks}

In teleoperation at the micro-nanoscale, haptic aids can help an operator respect task, environment task and system constraints while exploiting the flexibility of manual control to achieve the task. The constraints may be related to limitations of system hardware or requirements of a strategy of object manipulation. The choice of enabling a haptic aid depends on its contribution to task performance, including:

- Utility: does it do what users need?

- Accuracy: how much better does the user perform the task with the aid?

- Robustness: how robust is the aid depending on the objects manipulated and the manipulator used?

- Usability: how easy and pleasant is the aid to use? 
Table 1 summarizes the content of four evaluations of augmented teleoperation systems. The first two (Vogl, Ma, \& Sitti, 2006; Onal \& Sitti, 2009) were aimed at validating the usability of the system; whereas, the other two (Ammi, Ladjal, \& Ferreira, 2006; Ammi \& Ferreira, 2007) were aimed at comparing design alternatives with regard to the use of visual and haptic guides. In the latter case, the experimental plan consists of several experimental conditions; for example, one condition with no haptic guide, which is the control condition, and another one with the haptic guide. This comparison was also aimed at validating the use of such guides. In the evaluations cited here, criteria were focused on task performance, such as position accuracy and completion time. A common weak point in these studies, however, is the lack of information regarding statistical validity.

Table 1

Descriptive summary of user-based evaluations of augmented micro-teleoperation systems for use in research.

\begin{tabular}{|c|c|c|c|c|c|c|}
\hline Study & Participants & System & Task & Measures & $\begin{array}{l}\text { Trials per } \\
\text { user }\end{array}$ & Conclusion \\
\hline $\begin{array}{l}\text { (Vogl, Ma, \& } \\
\text { Sitti, 2006) }\end{array}$ & $\begin{array}{l}6 \text { untrained } \\
\text { participants }\end{array}$ & $\begin{array}{l}\text { 3D visual and } \\
\text { haptic } \\
\text { reconstruction of } \\
\text { an AFM probe } \\
\text { touching a surface }\end{array}$ & $\begin{array}{l}\text { Reaching a 3D } \\
\text { target on, above, } \\
\text { or below the } \\
\text { surface of } 3 \\
\text { different } \\
\text { materials }\end{array}$ & $\begin{array}{l}\text { Positioning } \\
\text { accuracy, } \\
\text { completion } \\
\text { time, forces, } \\
\text { trajectories }\end{array}$ & $\begin{array}{l}8 \text { different } \\
\text { trials } \\
\text { repeated } 3 \\
\text { times }\end{array}$ & $\begin{array}{l}\text { Stable user } \\
\text { interface but } \\
\text { no proper } \\
\text { usability } \\
\text { evaluation }\end{array}$ \\
\hline $\begin{array}{l}\text { (Onal \& Sitti, } \\
\text { 2009) }\end{array}$ & 10 participants & $\begin{array}{l}\text { Side-view } \\
\text { reconstruction } \\
\text { with haptic } \\
\text { feedback on an }\end{array}$ & $\begin{array}{l}\text { Tip positioning } \\
\text { on, above, or } \\
\text { below the } \\
\text { surface of } 3\end{array}$ & $\begin{array}{l}\text { Positioning } \\
\text { accuracy, } \\
\text { reaching speed } \\
\text { (Steinfeld et }\end{array}$ & $\begin{array}{l}10 \text { different } \\
\text { trials }\end{array}$ & $\begin{array}{l}\text { Stable } \\
\text { transparent } \\
\text { system but } \\
\text { no usability }\end{array}$ \\
\hline
\end{tabular}




\begin{tabular}{|c|c|c|c|c|c|c|}
\hline & & $\begin{array}{l}\text { AFM probe } \\
\text { indenting a } \\
\text { surface at the } \\
\text { nanoscale }\end{array}$ & $\begin{array}{l}\text { different } \\
\text { materials }\end{array}$ & al., 2006) & & $\begin{array}{l}\text { evaluation } \\
\text { (no research } \\
\text { question or } \\
\text { hypothesis, } \\
\text { no control } \\
\text { group) }\end{array}$ \\
\hline $\begin{array}{l}\text { (Ammi, } \\
\text { Ladjal, \& } \\
\text { Ferreira, } \\
\text { 2006) }\end{array}$ & $\begin{array}{l}13 \text { experts, } \\
\text { students, } \\
\text { technicians }\end{array}$ & $\begin{array}{l}3 \mathrm{D} \text { visual and } \\
\text { haptic } \\
\text { reconstruction of } \\
\text { cell injection }\end{array}$ & Cell penetration & $\begin{array}{l}\text { Forces, } \\
\text { trajectories, } \\
\text { completion } \\
\text { time, user } \\
\text { appreciation }\end{array}$ & $\begin{array}{l}1 \text { trial in } \\
\text { each of the } 4 \\
\text { conditions }\end{array}$ & $\begin{array}{l}\text { Haptic } \\
\text { guides } \\
\text { reduced } \\
\text { completion } \\
\text { time and } \\
\text { were } \\
\text { appreciated. }\end{array}$ \\
\hline $\begin{array}{l}\text { (Ammi \& } \\
\text { Ferreira, } \\
\text { 2007) }\end{array}$ & $\begin{array}{l}9 \text { experts, } \\
\text { students, } \\
\text { technicians }\end{array}$ & $\begin{array}{l}\text { 3D visual } \\
\text { reconstruction and } \\
\text { haptic guides for } \\
\text { an AFM-based } \\
\text { micromanipulator }\end{array}$ & $\begin{array}{l}\text { Touching a } \\
\text { microsphere, } \\
\text { moving the } \\
\text { effector while } \\
\text { avoiding } \\
\text { obstacles in the } \\
\text { microscene }\end{array}$ & $\begin{array}{l}\text { Trajectories, } \\
\text { completion } \\
\text { time }\end{array}$ & $\begin{array}{l}1 \text { trial in } \\
\text { each of the } 4 \\
\text { conditions }\end{array}$ & $\begin{array}{l}\text { Haptic } \\
\text { guides } \\
\text { reduced } \\
\text { completion } \\
\text { time and } \\
\text { smoothed } \\
\text { trajectories. }\end{array}$ \\
\hline
\end{tabular}

Two pilot evaluations were carried out by the authors in an attempt to validate a haptic aid for adhesion-based strategies of manipulation in ambient environments with a tipless cantilever. The haptic aid was designed to convey interaction forces through a haptic device with non-constant force scaling factors. The haptic feedback without the aid used a constant force scaling factor. The aid was evaluated through the pilot studies, involving two virtual manipulation tasks.

The first study was aimed at novice users and evaluated the aid for the tasks of capture and release by adhesion in terms of the criteria of accuracy, time efficiency, and user 
satisfaction. The task consisted of moving four spheres from one substrate to another more adhesive substrate (Figure 13). The experimental plan consisted of three conditions: (C1) without haptics; (C2) with haptics and no aid; and (C3) with haptics and the aid. An analysis of variance (ANOVA) was applied to each response measure but did not reveal any significant effects of conditions. This result suggests that the three conditions influenced participant performance in a similar manner. Hypotheses of better performance with the haptic feedback and aid ( $\mathrm{C} 2$ and $\mathrm{C} 3$ ) were, therefore, not validated. The results of the subjective evaluation are presented in Figure 14. There were significant differences in perception of rapidity and accuracy. The participants felt faster with haptic feedback, although the difference with the aid was not significant. They also felt more precise with haptics and the aid. This perception of better performance seemed to emanate from participants' recall of their best trials, which were significantly better with haptics and the aid. However, on average, there was no significant difference in trial performance. Trial completion time did vary substantially, possibly due to limited subject familiarization/training with the haptic device.

a)
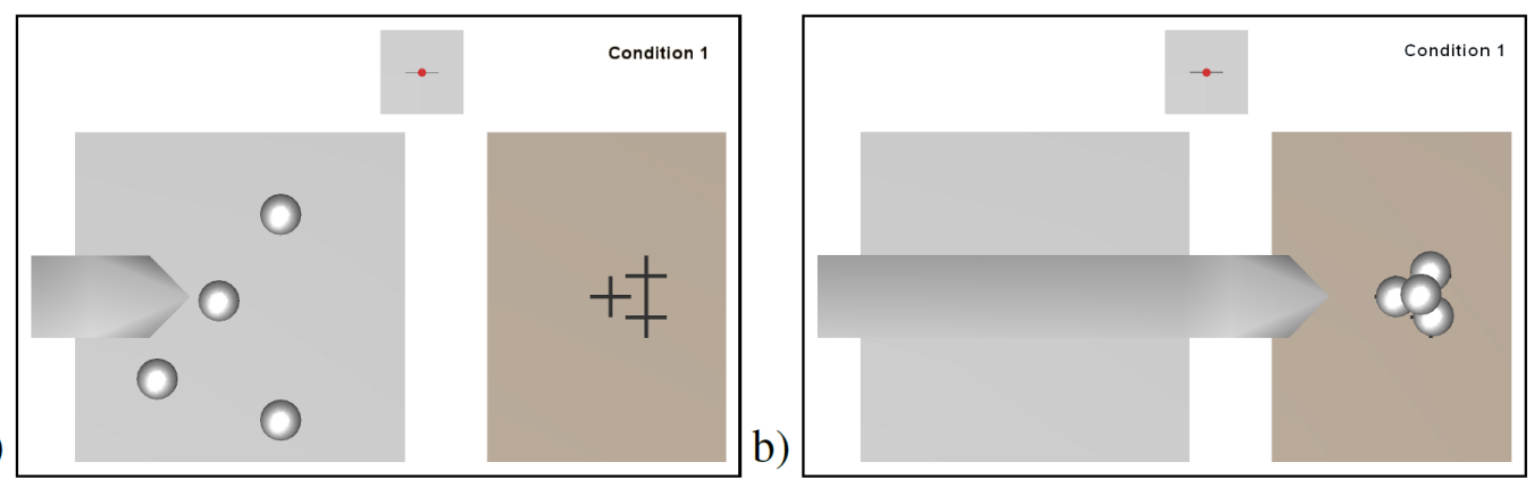

Figure 13. Top view of the virtual environment for the task of (a) capture and (b) release by adhesion. 


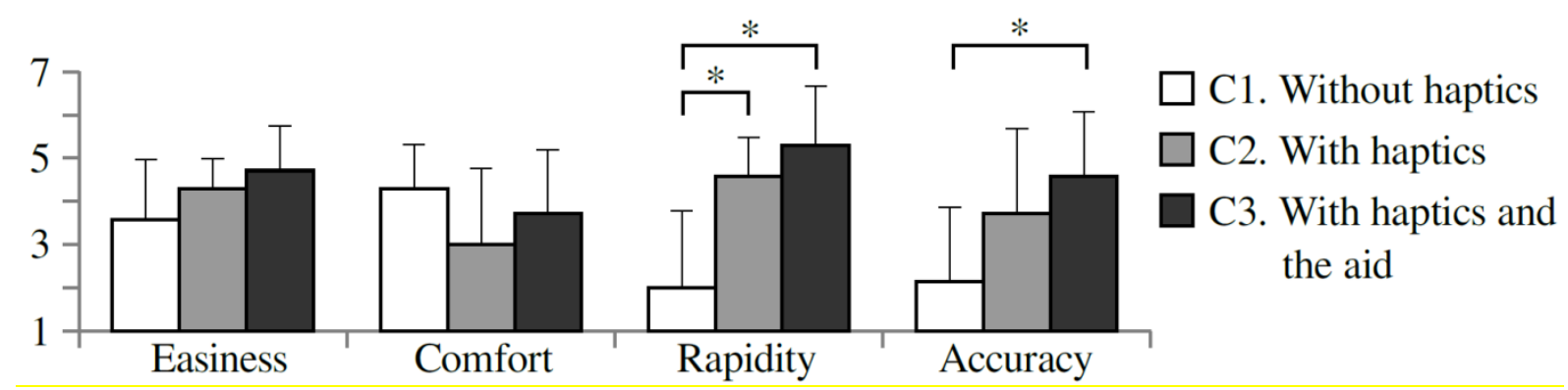

Figure 14. Means of subjective evaluations from 1 (very bad) to 7 (very good), according to the experimental conditions. Asterisks indicate significant effects of conditions.

The second pilot evaluation involved expert users, and evaluated the aid for the tasks of release by rolling, with the criterion of user satisfaction. The aid was expected to facilitate task completion rather than directly improve accuracy or efficiency. The task consisted of moving four spheres from one substrate to another by releasing them via rolling. The haptic aid resulted in $30 \%$ lower maximal forces than the no-aid condition. Results on subjective ratings of easiness and confidence revealed increases with the use of haptics and, even greater ratings, with the aid. These ratings were also strongly correlated.

In the case of virtual simulations of tasks, an obvious concern is the realism of the simulation. Some technical constraints of real setups may not be taken into account in the simulation. This situation can bias results with an optimistic interpretation in the case that the simulated task is easier to perform than the real one. For instance, in the above described studies, a lack of simulation of the limited strength of the cantilever, or the usual environmental perturbations (e.g., dust particles and electrostatic forces) could result in subject learning of unrealistic strategies of manipulation. Another example is the absence of a focal plane in the graphic rendering of the task scene, which facilitates vision-based manipulation. Such a simulation would lead to optimistic results for a test condition not providing haptic feedback. 


\section{User-based evaluation of haptic aids for nanoscience education}

In the context of nanoscience education, user-based evaluations of haptic aids have been studied in more detail, probably because of the huge population of intended users, including students from middle to graduate school. Some recent work has focused on the impact of virtual reality, mainly with haptic augmentation. Table 2 summarizes the content of these studies.

Persson et al. (2007) evaluated a haptic system in which students were able to manipulate a ligand and feel its interactions in docking with a molecule. The aim of the study was to determine what, if any, benefits haptics could have in an educational context in biomolecular chemistry. They found no obvious advantage for learning from the addition of force feedback to their system. Nevertheless, student answers to post-trial questions showed that force feedback sharpened the students' understanding of forces involved in the docking process.

In biology, Jones et al. (2003) used a virtual reality platform with a Phantom haptic device, connected to an AFM, to investigate the impact of its use on students' understanding of virus morphology, and of the AFM imaging process. This study found that students developed more accurate conceptions of virus morphology, when moving from a 2 DOF to 3 DOF manipulations of virus molecules. However, no difference was detected as a result of the use of haptics. A second experiment assessed the addition of different types of haptic feedback (presented through a 6 DOF Phantom device and a 2 DOF joystick) (Jones, Minogue, Tretter, Negishi, \& Taylor, 2006). They found the sensitivity of the haptic device, the number of haptic parameters, and the number of analogies students used to describe viruses were all positively correlated. A third study on the understanding of the structure of an animal cell showed mainly a motivational effect of using haptics (Minogue, Jones, Broadwell, \& Oppewall, 2006). 
For scanning microscopy education, Marchi et al. (2005) developed a multi-sensorial (visual, auditory, and haptic) simulation, equipped with a real-time physics engine. The simulation has been used for teaching one-dimensional nanophysical phenomenon and approach-retract (AR) force measurement to master's degree students. They reported that students provided a better description of phenomenon after use of the simulation as compared to a session where only a classical AFM was used. This finding may be attributable to the flexibility of virtual reality simulations, allowing for modification of different parameters from one extreme to the other and facilitating the observation of their influences.

The above finding also agrees with the conclusion of Finkelstein et al. (2005), who suggested that properly designed "computer simulations are useful tools for a variety of contexts that can promote student learning in appropriate contexts". However, the experimental plan of Marchi et al. (2005) did not directly compare the benefit of using haptic feedback for the educational process.

Millet, Lécuyer, Burkhardt, Haliyo, and Régnier (2008) evaluated the effects of using haptics and graphic analogies on student understanding of the AR phenomenon at the nanoscale. The graphic representations that were tested are illustrated in Figure 15. For the analogy, a magnet attached to a well-damped spring (touching a ferromagnetic surface) was chosen. The four experimental conditions included two haptic conditions (haptics; no haptics) and two graphics conditions (cantilever; analogy). Results showed that both haptic feedback and the analogy were appreciated by subjects and they had an influence on subject perception and understanding of the AR phenomenon. The addition of haptic feedback increased subject attention to forces involved in the AR phenomenon, and improved the perception of the influence of physical parameters, by providing more information. The magnetic-spring analogy helped subjects in the early phases of understanding force-distance curves on the AR phenomenon. 
Table 2

Descriptive summary of related studies in nanoscience education.

\begin{tabular}{|c|c|c|c|c|c|c|}
\hline Study & Participants & Device & Stimuli & Measures & $\begin{array}{l}\text { Dependent } \\
\text { variable(s) }\end{array}$ & Conclusion \\
\hline $\begin{array}{l}\text { (Persson et } \\
\text { al., 2007) }\end{array}$ & $\begin{array}{l}23 \text { undergraduate } \\
\text { students }\end{array}$ & $\begin{array}{l}\text { 6D } \\
\text { Phantom }\end{array}$ & $\begin{array}{l}\text { Molecular } \\
\text { docking } \\
\text { simulation }\end{array}$ & $\begin{array}{l}\text { Knowledge } \\
\text { tests, opinion } \\
\text { questionnaire, } \\
\text { docking tasks }\end{array}$ & $\begin{array}{l}\text { Understanding of } \\
\text { docking } \\
\text { interactions }\end{array}$ & $\begin{array}{l}\text { No obvious } \\
\text { benefits of } \\
\text { haptics for } \\
\text { learning }\end{array}$ \\
\hline $\begin{array}{l}\text { (Jones, } \\
\text { Andre, } \\
\text { Superfine, } \\
\& \text { Taylor, } \\
\text { 2003) }\end{array}$ & $\begin{array}{l}43 \text { high school } \\
\text { students }\end{array}$ & $\begin{array}{l}\text { 6D } \\
\text { Phantom }\end{array}$ & $\begin{array}{l}\text { Teleoperation of } \\
\text { an AFM probe } \\
\text { touching a virus }\end{array}$ & $\begin{array}{l}\text { Knowledge } \\
\text { tests, opinion } \\
\text { questionnaire, } \\
\text { clay modeling, } \\
\text { interview }\end{array}$ & $\begin{array}{l}\text { Understanding of } \\
\text { viruses and of } \\
\text { AFM imaging } \\
\text { process }\end{array}$ & $\begin{array}{l}\text { Motivational } \\
\text { effect and } \\
\text { more accurate } \\
\text { conceptions of } \\
\text { virus } \\
\text { morphology } \\
\text { but no } \\
\text { benefits from } \\
\text { haptics }\end{array}$ \\
\hline $\begin{array}{l}\text { (Jones, } \\
\text { Minogue, } \\
\text { Tretter, } \\
\text { Negishi, \& } \\
\text { Taylor, } \\
2006)\end{array}$ & $\begin{array}{l}36 \text { high school } \\
\text { students }\end{array}$ & $\begin{array}{l}\text { mouse, 2D } \\
\text { joystick, } \\
\text { 3D } \\
\text { Phantom }\end{array}$ & $\begin{array}{l}\text { Simulation of } \\
\text { an AFM probe } \\
\text { touching a virus }\end{array}$ & $\begin{array}{l}\text { Knowledge } \\
\text { tests, opinion } \\
\text { questionnaire }\end{array}$ & $\begin{array}{l}\text { Understanding of } \\
\text { physical } \\
\text { properties of } \\
\text { viruses }\end{array}$ & $\begin{array}{l}\text { Understanding } \\
\text { was better } \\
\text { with increased } \\
\text { sensitivity of } \\
\text { haptic device }\end{array}$ \\
\hline $\begin{array}{l}\text { (Minogue, } \\
\text { Jones, } \\
\text { Broadwell, } \\
\&\end{array}$ & $\begin{array}{l}80 \text { middle school } \\
\text { students }\end{array}$ & $\begin{array}{l}\text { 6D } \\
\text { Phantom }\end{array}$ & $\begin{array}{l}\text { Simulation of } \\
\text { an animal cell }\end{array}$ & $\begin{array}{l}\text { Knowledge } \\
\text { tests, opinion } \\
\text { questionnaire }\end{array}$ & $\begin{array}{l}\text { Understanding of } \\
\text { the structure and } \\
\text { function of an } \\
\text { animal cell }\end{array}$ & $\begin{array}{l}\text { Motivational } \\
\text { effect of } \\
\text { haptics }\end{array}$ \\
\hline
\end{tabular}




\begin{tabular}{|c|c|c|c|c|c|c|}
\hline $\begin{array}{l}\text { Oppewall, } \\
\text { 2006) }\end{array}$ & & & & & & \\
\hline $\begin{array}{l}\text { (Marchi et } \\
\text { al., 2005) }\end{array}$ & $\begin{array}{l}60 \text { undergraduate } \\
\text { students }\end{array}$ & 1D Ergos & $\begin{array}{l}\text { AR cycle of real } \\
\text { and virtual } \\
\text { AFM probes }\end{array}$ & $\begin{array}{l}\text { Knowledge tests } \\
\text { with curve } \\
\text { drawing, } \\
\text { opinion } \\
\text { questionnaire }\end{array}$ & $\begin{array}{l}\text { Understanding of } \\
\text { AFM and AR } \\
\text { cycles }\end{array}$ & $\begin{array}{l}\text { Better } \\
\text { understanding } \\
\text { due to the use } \\
\text { of virtual } \\
\text { simulations }\end{array}$ \\
\hline $\begin{array}{l}\text { (Millet, } \\
\text { Lécuyer, } \\
\text { Burkhardt, } \\
\text { Haliyo, \& } \\
\text { Régnier, } \\
\text { 2008) }\end{array}$ & $\begin{array}{ll}45 & \text { graduate } \\
\text { students } & \end{array}$ & $\begin{array}{l}\text { 6D } \\
\text { Virtuose }\end{array}$ & $\begin{array}{l}\text { AR cycle of } \\
\text { virtual AFM } \\
\text { probes }\end{array}$ & $\begin{array}{l}\text { Knowledge tests } \\
\text { with curve } \\
\text { drawing and } \\
\text { curve choosing, } \\
\text { opinion } \\
\text { questionnaire }\end{array}$ & $\begin{array}{l}\text { Understanding of } \\
\text { AFM and AR } \\
\text { cycles }\end{array}$ & $\begin{array}{l}\text { Motivational } \\
\text { effect, better } \\
\text { understanding } \\
\text { with the use } \\
\text { of haptics and } \\
\text { graphic } \\
\text { analogies. }\end{array}$ \\
\hline
\end{tabular}

Taken together, these results suggest that future teaching aids for nanoscale phenomena could combine both haptic feedback and graphic analogies. 

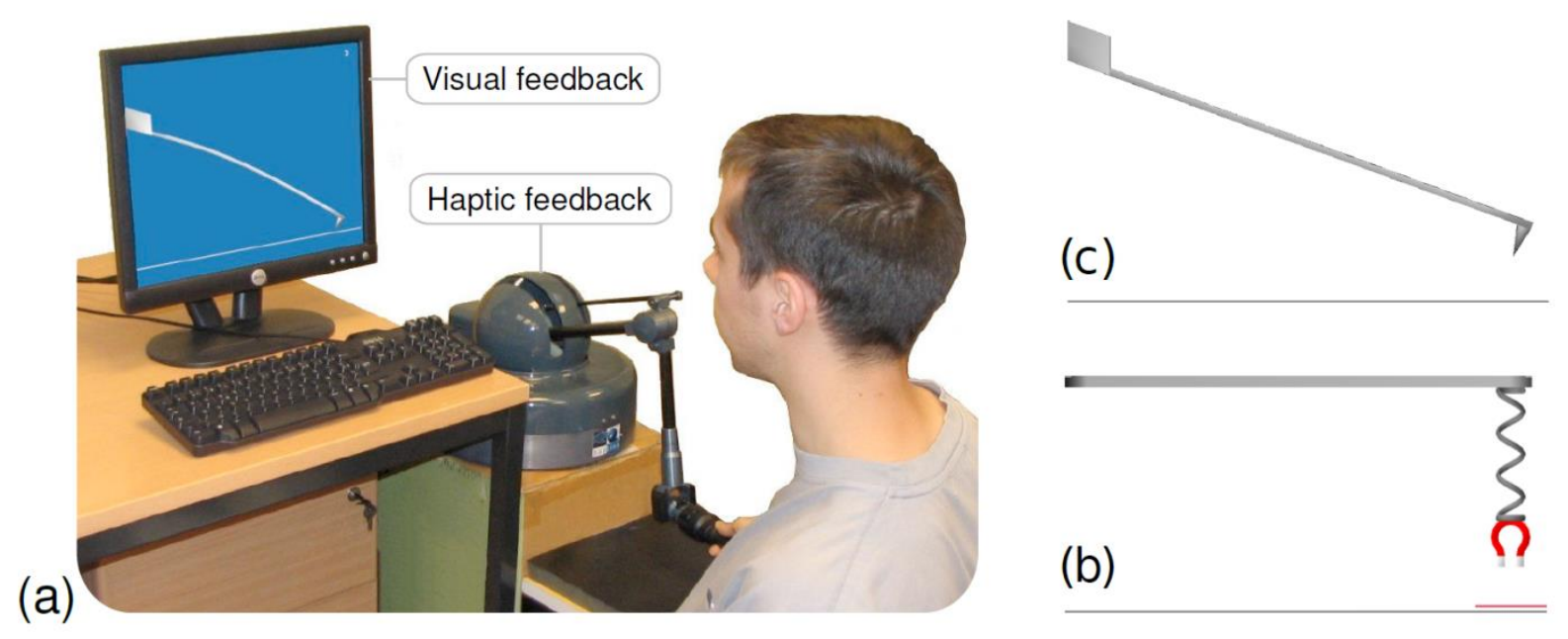

Figure 15. Plate (a) Overview of the experimental set-up. Plate (b,c) Virtual representations of the cantilever and its magnet-spring analogy, during approach and retract phases. Reprinted with permission from Elsevier from Millet, Lécuyer, Burkhardt, Haliyo, and Régnier (2013).

\section{Summary on User-Based Tests}

The examples of evaluations presented above provide some insight into the benefit of haptic feedback at the micro-nanoscale. Feedback improves certain parameters, such as operator confidence and awareness of the limits of forces that can be applied to a system. However, other response measures remain unchanged, such as task completion time. In addition, the development of educational applications requires more rigorous in-situ evaluations of educational haptically-augmented platforms (i.e., in a learning sequence and with a control group). There is also a need for comparative studies on both the accuracy and the usability of existing manipulation strategies, with or without haptics.

To obtain a deeper understanding of the real benefit of a haptic feedback, systematic studies based on a sufficient number of users should be performed, and should include as many relevant parameters as possible, including the choice of the haptic feedback (virtual guides or high fidelity rendering of interaction forces), the use of modal or multi-modal 
feedback (vision, sound, tactile, etc.), the choice of displacement mode (velocity, position, etc.), and the ergonomics of the haptic device, etc. A broad study still needs to be conducted to determine which parameter settings may improve user performance in haptically-aided micro-nanoscale applications.

\section{CONCLUSION, GUIDELINES AND PERSPECTIVES}

This chapter has reviewed the major types of teleoperation systems, and has shown that several proofs of concept are available for the micro-nanoscale. The development of these haptic feedback teleoperation systems, for industrial and biological applications at the micronanoscale, offers promising solutions to improve operator knowledge and the efficiency of task performance.

Based on prior research, design guidelines to ensure the efficiency of teleoperation systems can be derived. These guidelines are summarized in Figure 16. First, haptic teleoperation systems must be adapted to specific applications. The needs of end users must be carefully defined, as well as the level of expertise of the users. These characteristics will largely influence the choice of haptic feedback. The type of teleoperation system should be selected depending on the application.

Second, as shown in Figure 16, the system setup and/or software must be considered. Direct and augmented teleoperation set-ups already exist for micro-nanoscale applications. The availability of position and/or force sensors must be checked for specific work environments. These sensors must provide enough information about the phenomena that are to be rendered haptically. The update rate of sensors should, ideally, be higher than $1 \mathrm{kHz}$. If vision is used as a position sensor, this update rate may not be achievable. Consequently, vision sensors should be combined with other modalities to ensure that highly varying 
phenomena are measured with a high update rate. Vision systems can provide indications of events in the global scene.

If a new set-up has to be designed, either contact or non-contact manipulation can be chosen. Actuation and sensing elements should be optimized, to enable high update rates. In the case of augmented or virtual teleoperation simulation, software development tools must be available. The simulation software must provide force information (most molecular simulation software provides energy information that must then be converted into force information). Trade-offs may need to be made between the accuracy of the simulation and the simulation time. An update rate of $1 \mathrm{kHz}$ is desired. To decrease the simulation time, several solutions can be considered: simulation models can be simplified; object interaction forces can be pre-computed; and deformations of objects can be neglected, etc. In the case of augmented teleoperation, the simulation can be updated regularly based on information coming from the real scene, in order to avoid deviations or drift as a result of inaccuracy in registration of the simulation with reality.

Third, the flowchart depicted in Figure 16 indicates that when the system set-up and/or simulation software are available, the next module to consider is the coupling between the haptic control device and tool motion in the micro- or nano-environment. The system must transform the input of the operator to use it to control the position of the tool and/or object. Similarly, the system must compute the haptic force based on the available force and/or position information measured by sensors at the tool tip. The simplest coupling consists of two scaling factors to scale down the position of the haptic control, and to scale up the interaction forces. It can also be much more complex to provide different manipulation modes, based on, for example, velocity control of an object. This choice depends on the application and level of operator expertise. Actual interaction forces can be transmitted as reliably as possible, or virtual guides can assist the operator in a given task. In any case, the 
coupling must remain stable. Several approaches based on stability or passivity controllers have been proposed and demonstrated. If reliable rendering of the interaction force is desired, the coupling should also ensure transparency of the micro-nanoscale environment for the user. Viscosity can be added to the control to ensure stability and to avoid deterioration of the transparency.

Fourth, after obtaining the desired teleoperation system, evaluations must be conducted, including user testing. Such testing may have multiple purposes; for example, to identify usability problems, validate the system, or to compare design alternatives. Designing a user-based evaluation includes the following steps:

- choosing a task that is representative of the goals of the system;

- designing an experimental plan considering the statistical hypotheses and the dependent and independent variables;

- $\quad$ selecting measures (accuracy, usability, etc.) and designing the test procedure with care to avoid any statistical bias;

- $\quad$ recruiting a representative sample of the intended $u s e r s ;{ }^{8}$

- applying adequate statistical analyses; in particular, the results should include a statement of the statistical probability that any differences may be a result of chance.

\footnotetext{
${ }^{8}$ The number of participants required can be calculated if you know the variance in the data (from a previous similar study or a pilot study) and the confidence level required (Lewis, 2006).
} 


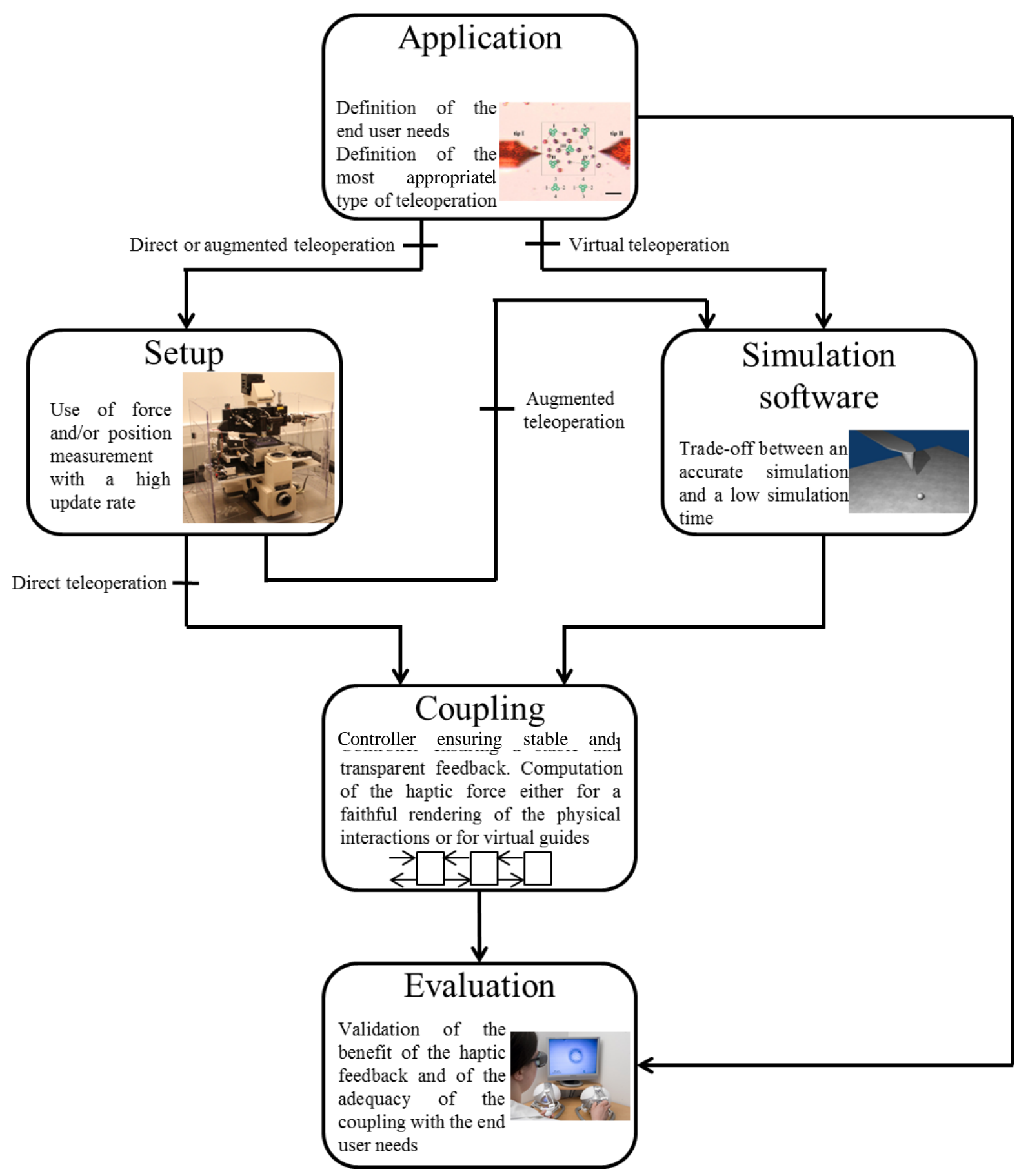

Figure 16. Design guidelines to ensure an efficient teleoperation system. Image of the AFM tips reproduced from Xie and Régnier (2009).

On the basis of the above system development and validation process, several directions of future research can be identified. Currently, most haptic teleoperation systems use commercially available haptic devices. However, their performance is not adapted to the 
properties of object interactions at the microscale that must be transmitted to users for task/enviroment transparency, as well as the range of forces that must be sent, and the response time. Innovative device architectures, such as that represented by the prototype developed by Mohand-Ousaid, Millet, Régnier, Haliyo, and Hayward (2012), provide transparent and highly dynamic force renderings, based on the use of different types of drivemotors and viscous couplers. Such devices can transmit high-fidelity haptic feedback on rapidly varying phenomena.

In addition, research needs to be conducted on the haptic control design, including definition of the most appropriate shape for specific applications. Such design might replicate common tools, including grippers, to avoid long learning processes and to promote ease-ofuse. There is a need for mechanical designers to work with end users and ergonomists to define the architecture of a device and to perform fabrication.

The prior research on direct teleoperation (reviewed as part of this chapter) was performed by research teams and tested on their own set-ups. Promising results have been generated and demonstrate that direct teleoperation is now a mature field that can benefit small-scale industrial projects, where precision and flexibility in microassembly are required. However, to go from laboratory experiments to industrial projects, the needs of the end users must be redefined. Consequently, research on future teleoperation systems should be performed in close collaboration with industrial and ergonomics professionals, in order to yield optimized designs of haptic devices and control couples.

Virtual and augmented teleoperation greatly facilitate micromanipulation, either by providing a virtual environment to test manipulation protocols, or by enhancing available feedback in direct teleoperation. However, for the moment, their use is limited due to limited accuracy of simulation models. Improving the accuracy and the computational efficiency of such models would greatly enhance the effectiveness of virtual and augmented teleoperation 
systems. Future research needs to focus on modeling the physical phenomena ruling the behavior of microscopic objects, and developing models that produce outputs in agreement with experimental results. This would enable progress on virtual and augmented teleoperation, as well as on automated manipulation.

In augmented teleoperation, the use of multi-modal feedback (i.e., visual, audio, and haptic) at the microscale has received little attention. System design metaphors for presenting multi-modal feedback need to be proposed. The use of tactile displays should also be considered. This type of research requires systematic user-based tests to determine the benefit of each feedback modality for the particular application. The insights of psychologists might prove to be beneficial on this topic. In addition, current systems are either fully automated, which enables high frequency operations, or fully teleoperated, which has the advantage of flexibility. Substantial benefits may occur if these two modalities are combined. Some tasks could be performed automatically, such as gripping in a pick-and-place operation, while others could remain under the control of the operator, such as the choice of the trajectory and the release location of the part. Again, such research requires close collaboration with endusers, to correctly define the needs and the constraints of each application.

In the next few years, we expect that versatile haptic feedback teleoperation systems will become widely used at the micro-nanoscale. We also expect these systems to substantially benefit both industrial end users in the conception and fabrication of innovative materials or molecules, as well as students in greater comprehension of micro-nanoscale phenomena. 


\section{REFERENCES}

Abe, N., Mizokami, R., Kinoshita, Y., \& He, S. (2007). Providing simulation of medical manipulation with haptic feedback. 17th International Conference on Artificial Reality and Telexistence, (pp. 143-148).

Ammi, M., \& Ferreira, A. (2007). Robotic assisted micromanipulation system using virtual fixtures and metaphors. IEEE International Conference on Robotics and Automation, (pp. 454-460).

Ammi, M., Ladjal, H., \& Ferreira, A. (2006). Evaluation of 3D pseudo-haptic rendering using vision for cell micromanipulation. IEEE/RSJ International Conference on Intelligent Robots and Systems, (pp. 2115-2120).

Andersen, K. N., Carlson, K., Petersen, D. H., Mølhave, K., Eichhorn, V., Fatikow, S., Bøggild, P. (2008). Electrothermal microgrippers for pick-and-place operations. Microelectronic Engineering, 85(5-6), 1128-1130.

Andersen, K., Petersen, D., Carlson, K., Molhave, K., Sardan, O., Horsewell, A., . . B Boggild, P. (2009). Multimodal electrothermal silicon microgrippers for nanotube manipulation. IEEE Transactions on Nanotechnology, 8(1), 76-85.

Arai, F., Ogawa, M., \& Fukuda, T. (2000). Indirect manipulation and bilateral control of the microbe by the laser manipulated microtools. IEEE/RSJ International Conference on Intelligent Robots and Systems, (pp. 665-670).

Ashkin, A., Dziedzic, J. M., Bjorkholm, J. E., \& Chu, S. (1986). Observation of a single-beam gradient force optical trap for dielectric particles. Optics Letters, 11(5), 288-290.

Bargiel, S., Rabenorosoa, K., Clévy, C., Gorecki, C., \& Lutz P. (2010). Towards microassembly of hybrid MOEMS components on reconfigurable silicon free-space microoptical bench. Journal of Micromechanics and Microengineering, 20(4).

Basha, M. A., Dechev, N., Safavi-Naeini, S., \& Chaudhuri, S. K. (2007). A scalable 1 x N optical MEMS switch architecture utilizing a microassembled rotating micromirror. IEEE journal of selected topics in quantum electronics, 13(2), 336-347.

Bolopion, A., \& Régnier, S. (2013). A review of haptic feedback teleoperation systems for micromanipulation and microassembly. IEEE Transactions on Automation Science and Engineering, 10, 496-502. 
Bolopion, A., Cagneau, B., \& Régnier, S. (2009). 2D micro teleoperation with force feedback. IEEE/RSJ International Conference on Intelligent Robots and Systems, (pp. 32653270).

Bolopion, A., Cagneau, B., Haliyo, S., \& Régnier, S. (2009). Analysis of stability and transparency for nanoscale force feedback in bilateral coupling. Journal of Micro Nano Mechatronics, 4, 145-158.

Bolopion, A., Cagneau, B., Redon, S., \& Régnier, S. (2010). Comparing position and force control for interactive molecular simulators with haptic feedback. Journal of Molecular Graphics and Modelling, 29(2), 280-289.

Bolopion, A., Cagneau, B., Redon, S., \& Régnier, S. (2011). Variable gain haptic coupling for molecular simulation. IEEE World Haptics Conference, (pp. 469-474).

Bolopion, A., Dahmen, C., Stolle, C., Haliyo, S., Régnier, S., \& Fatikow, S. (2012). Vision based haptic feedback for remote micromanipulation in a SEM environment. International Journal of Optomechatronics, 6(3), 236-252.

Bolopion, A., Stolle, C., Tunnell, R., Haliyo, S., Régnier, S., \& Fatikow, S. (2011). Remote microscale teleoperation through virtual reality and haptic feedback. IEEE/RSJ International Conference on Intelligent Robots and Systems, (pp. 894-900).

Bolopion, A., Xie, H., Haliyo, S., \& Régnier, S. (2012). Haptic teleoperation for 3D microassembly of spherical objects. IEEE/ASME Transaction on Mechatronics, 17(1), 116-127.

Boukhnifer, M., \& Ferreira, A. (2006). Wave-based passive control for transparent microteleoperation system. Robotics and Autonomous Systems, 54(7), 601-615.

Boukhnifer, M., \& Ferreira, A. (2007). Hळ loop shaping bilateral controller for a two-fingered tele-micro-manipulation system. IEEE Transactions on Control Systems Technology, 15(5), 891-905.

Bowman, R., Preece, D., Gibson, G., \& Padgett, M. (2011). Stereoscopic particle tracking for 3D touch, vision and closed-loop control in optical tweezers. Journal of Optics, 13(4), 044003.

Brooks Jr., F. P., Ouh-Young, M., Batter, J. J., \& Kilpatrick, P. J. (1990). Project GROPE Haptic displays for scientific visualization. Conference on Computer graphics and interactive techniques, (pp. 177-185).

Bukusoglu, I., Basdogan, C., Kiraz, A., \& Kurt, A. (2008). Haptic manipulation of microspheres using optical tweezers under the guidance of artificial force fields. Presence: Teleoperators and Virtual Environments, 17(4), 344-364.

Bustamante, C., Bryant, Z., \& Smith, S. (2003). Ten years of tension: Single-molecule DNA mechanics. Nature, 421(6921), 423-427. 
Cho, S.-Y., \& Shim, J.-H. (2004). A new micro biological cell injection system. IEEE/RSJ International Conference on Intelligent Robots and Systems, (pp. 1642-1647).

Daunay, B., \& Régnier, S. (2009). Stable six degrees of freedom haptic feedback for flexible ligand-protein docking. Computer Aided Design, 41(12), 886-895.

de Vries, A. H., Krenn, B. E., van Driel, R., \& Kanger, J. S. (2005). Micro magnetic tweezers for nanomanipulation inside live cells. Biophysical Journal, 88(3), 2137-2144.

Dix, A., Finlay, J. E., Abowd, G. D., \& Beale, R. (2003). Human-Computer Interaction (3 ${ }^{\text {rd }}$ ed.). Upper Saddle River, NJ: Prentice Hall.

Fahlbusch, S., Shirinov, A., \& Fatikow, S. (2002). AFM-based micro force sensor and haptic interface for a nanohandling robot. IEEE/RSJ International Conference on Intelligent Robots and Systems, (pp. 1772-1777).

Falvo, M., Clary, G., Helser, A., Paulson, S., Taylor II, R., Chi, V., . . Superfine, R. (1999). Nanomanipulation experiments exploring frictional and mechanical properties of carbon nanotubes. Journal of Microscopy and Microanalysis, 4, 504-512.

Ferreira, A., \& Mavroidis, C. (2006). Virtual reality and haptics for nanorobotics. IEEE Robotics and Automation Magazine, 13(3), 78-92.

Finkelstein, N. D., Adams, W. K., Keller, C. J., Kohl, P. B., Perkins, K. K., Podolefsky, N. S., . . LeMaster, R. (2005). When learning about the real world is better done virtually: A study of substituting computer simulations for laboratory equipment. Physical Review Special Topics - Physics Education Research, 1(1), 010103.

Fok, L., Liu, Y., \& Li, W. (2005). Modeling of nanomanipulation with an integrated teleoperated system. IEEE International Conference on Robotics and Biomimetics, (pp. 83-88).

Gao, Z., \& Lécuyer, A. (2009). Path-planning and manipulation of nanotubes using visual and haptic guidance. IEEE International Conference on Virtual Environments, HumanComputer Interfaces and Measurements Systems, (pp. 1-5).

Ghanbari, A., Abdi, H., Horan, B., Nahavandi, S., Xiaoqi, C., \& Wenhui, W. (2010). Haptic guidance for microrobotic intracellular injection. IEEE RAS and EMBS International Conference on Biomedical Robotics and Biomechatronics, (pp. 162-167).

Gosse, C., \& Croquette, V. (2002). Magnetic tweezers: Micromanipulation and force measurement at the molecular level. Biophysical Journal, 82(6), 3314-3329.

Grange, S., Conti, F., Helmer, P., Rouiller, P., \& Baur, C. (2001). The delta haptic device as a nanomanipulator. SPIE Microrobotics and Microassembly III, (pp. 100-111).

Grudinin, S., \& Redon, S. (2010). Practical modeling of molecular systems with symmetries. Journal of Computational Chemistry, 31(9), 1799-1814. 
Guthold, M., Falvo, M., Matthews, W. G., Paulson, S., Mullin, J., Lord, S., . . Taylor, R. M. (1999). Investigation and modification of molecular structures with the nanoManipulator. Journal of Molecular Graphics and Modelling, 17 (3-4), 187-197.

Guthold, M., Falvo, M., Matthews, W., Paulson, S., Washburn, S., Erie, D., . . T Taylor II, R. (2000). Controlled manipulation of molecular samples with the nanoManipulator. IEEE/ASME Transactions on Mechatronics, 5(2), 189-198.

Hamdi, M., Ferreira, A., Sharma, G., \& Mavroidis, C. (2008). Prototyping bio-nanorobots using molecular dynamics simulation and virtual reality. Microelectronics Journal, 39(2), 190-201.

Hamdi, M., Sharma, G., Ferreira, A., \& Mavroidis, C. (2005). Molecular mechanics simulation of bio-nanorobotic components using force feedback. IEEE International Conference on Robotics and Biomimetics, (pp. 105-110).

Hatamura, Y., \& Morishita, H. (1990). Direct coupling system between nanometer world and human world. IEEE International Conference on Micro Electro Mechanical Systems, (pp. 203-208).

Hollis, R., Salcudean, S., \& Abraham, D. (1990). Toward a tele-nanorobotic manipulation system with atomic scale force feedback and motion resolution. IEEE International Conference on Micro Electro Mechanical Systems, (pp. 115-119).

Ikin, L., Carberry, D. M., Gibson, G. M., Padgett, M. J., \& Miles, M. J. (2009). Assembly and force measurement with SPM-like probes in holographic optical tweezers. New Journal of Physics, 11(2).

ISO 9241-11 (1998). Ergonomic requirements for office work with visual display terminals (VDTs) - Part 11: Guidance on usability. ISO, Geneva, Switzerland.

Jones, M. G., Andre, T., Superfine, R., \& Taylor, R. (2003). Learning at the nanoscale: The impact of students' use of remote microscopy on concepts of viruses, scale, and microscopy. Journal of Research in Science Teaching, 40(3), 303-322.

Jones, M. G., Minogue, J., Tretter, T. R., Negishi, A., \& Taylor, R. (2006). Haptic augmentation of science instruction: Does touch matter? Science Education, 90, 111123.

Kim, D.-H., Kim, B. K., Kang, H., \& Ju, B.-K. K. (2003). Development of a piezoelectric polymer-based sensorized microgripper for microassembly and micromanipulation. IEEE/RSJ International Conference on Intelligent Robots and Systems, (pp. 18641869).

Kim, D.-H., Kim, B., Yun, S., \& Kwon, S. (2004). Cellular force measurement for force reflected biomanipulation. IEEE International Conference on Robotics and Automation, (pp. 2412-2417). 
Kim, D.-H., Kim, K., Kim, K.-Y., \& Cha, S.-M. (2001). Dexterous teleoperation for micro parts handling based on haptic/visual interface. International Symposium on Micromechatronics and Human Science, (pp. 211-217).

Kim, J., Janabi-Sharifi, F., \& Kim, J. (2008). Haptic feedback based on physically based modeling for cellular manipulation systems. In M. Ferre (Ed.), Haptics: Perception, Devices and Scenarios (Vol. 5024, pp. 661-667). Springer Berlin Heidelberg.

Kim, S.-G., \& Sitti, M. (2006). Task-based and stable telenanomanipulation in a nanoscale virtual environment. IEEE Transactions on Automation Science and Engineering, 3(3), 240-247.

Ladjal, H., Hanus, J. L., Pillarisetti, A., Keefer, C., Ferreira, A., \& Desai, J. P. (2012). Reality-based real-time cell indentation simulator. IEEE/ASME Transactions on Mechatronics, 17(2), 239-250.

Ladjal, H., Hanus, J.-L., \& Ferreira, A. (2011). Microrobotic simulator for assisted biological cell injection. IEEE/RSJ International Conference on Intelligent Robots and Systems, (pp. 1315-1320).

Lai-Yuen, S., \& Lee, Y.-S. (2006). Energy-field optimization and haptic-based molecular docking and assembly search system for computer-aided molecular design (CAMD). Symposium on Haptic Interfaces for Virtual Environment and Teleoperator Systems, (pp. 233-240).

Le, V. T., Nahavandi, S., \& Creighton, D. (2010). A haptic training environment for the heart myoblast cell injection procedure. IEEE International Conference on Control Automation Robotics \& Vision, (pp. 448-452).

Lee, S.-W., Lee, T., \& Lee, Y.-G. (2007). Stable manipulating of nanowires by line optical tweezers with haptic feedback. Optical Trapping and Optical Micromanipulation IV, 6644.

Lee, Y.-G., \& Lyons, K. W. (2004). Smoothing haptic interaction using molecular force calculations. Computer-Aided Design, 36(1), 75-90.

Lewis, J. R. (2006). Sample sizes for usability tests: mostly math, not magic. Magazine interactions - Waits \& Measures, 13(6), 29-33.

Liu, L., Jiao, N., Tian, X., Dong, Z., Xi, N., Li, W., \& Wang, Y. (2006). Development of a haptic user interface for surface sensing and nanomanipulation based on atomic force microscope. IEEE International Conference on Nano/Micro Engineered and Molecular Systems, (pp. 900-904).

Liu, X., Sun, Y., Wang, W., \& Lansdorp, B. (2007). Vision-based cellular force measurement using an elastic microfabricated device. Journal of Micromechanics and Microengineering, 17(7), 1281-1288. 
Marchi, F., Marliere, S., Urma, D., Florens, J.-L., Chevrier, J., Cadoz, C., \& Luciani, A. (2005). Interactive learning of nanophysics phenomena. International Conference on Multimedia and ICTs in Education, (pp. 510-515).

Marchi, F., Urma, D., Marliere, S., Florens, J. L., Besancon, A., Chevrier, J., \& Luciani, A. (2005). Educational tool for nanophysics using multisensory rendering. World Haptics Conference, (pp. 473-474).

Marliere, S., Urma, D., Florens, J., \& Marchi, F. (2004). Multi-sensorial interaction with a nano-scale phenomenon: the force curve. Eurohaptics, (pp. 246-252).

Maugis, D. (2000). Contact, Adhesion, and Rupture of Elastic Solids. Springer series in solidstate sciences, 130. Berlin, Germany: Springer-Verlag.

Millet, G., Lécuyer, A., Burkhardt, J., Haliyo, S., \& Régnier, S. (2008). Improving perception and understanding of nanoscale phenomena using haptics and visual analogy. EuroHaptics, (pp. 847-856).

Millet, G., Lécuyer, A., Burkhardt, J.-M., Haliyo, S., Régnier, S. (2013). Haptics and graphic analogies for the understanding of atomic force microscopy. International Journal of Human-Computer Studies, 71 (5), 608-626.

Minogue, J., Jones, M. G., Broadwell, B., \& Oppewall, T. (2006). The impact of haptic augmentation on middle school students' conceptions of the animal cell. Virtual Reality, 10(3), 293-305.

Mohand Ousaid, A., Millet, G., Régnier, S., Haliyo, S., \& Hayward, V. (2012). Haptic Interface Transparency Achieved Through Viscous Coupling. The International Journal of Robotics Research, 31(3), 319-329.

Murayama, J., Shimizu, H., Nam, C. S., Satoh, H., \& Sato, M. (2007). An educational environment for chemical contents with haptic interaction. International Conference on Cyberworlds, (pp. 346-352).

Nagata, H., Mizushima, H., \& Tanaka, H. (2002). Concept and prototype of protein-ligand docking simulator with force feedback technology. Bioinformatics, 18(1), 140-146.

Neuman, K. C., \& Block, S. M. (2004). Optical trapping. The Review of Scientific Instruments, 75(9), 2787-2809.

Ni, Z., Bolopion, A., Agnus, J., Benosman, R., \& Régnier, S. (2012). Asynchronous eventbased visual shape tracking for stable haptic feedback in microrobotics. IEEE Transactions on Robotics, 28(5), 1081-1089.

Ni, Z., Pacoret, C., Benosman, R., Ieng, S., \& Régnier, S. (2011). Asynchronous event based high speed vision for microparticle tracking. Journal of microscopy, 245(3), 236-244.

Nielsen, J. (1993). Usability Engineering. Academic Press. 
Niguès, A., Venant, N., Rodrigues, M., Comin, F., Florens, J., \& Marchi, F. (2012). Haptic localization and shape recognition of nano objects. IEEE/RSJ International Conference on Intelligent Robots and Systems, (pp. 2319-2324).

Okamura, A. M., Richard, C., \& Cutosky, M. R. (2002). Feeling is believing: using a forcefeedback joystick to teach dynamic systems. Journal of Engineering Education, 91(3), 345-349.

Onal, C. D., \& Sitti, M. (2009). A scaled bilateral control system for experimental onedimensional teleoperated nanomanipulation. The International Journal of Robotics Research, 28(4), 484-497.

Onal, C. D., \& Sitti, M. (2010). Teleoperated 3D force feedback from the nanoscale with an atomic force microscope. IEEE Transactions on nanotechnology, 9(1), 46-54.

Onda, K., \& A. F. (2012). Multi-beam bilateral teleoperation of holographic optical tweezers. Optics Express, 20(4), 3633-3641.

Ouh-Young, M., Pique, M., Hughes, J., Srinivasan, N., \& Brooks Jr., F. (1988). Using a manipulator for force display in molecular docking. IEEE International Conference on Robotics and Automation, (pp. 1824-1829).

Pacoret, C., Bowman, R., Gibson, G., Haliyo, S., Carberry, D., Bergander, A., . . Padgett, M. (2009). Touching the microworld with force-feedback optical tweezers. Optics Express, 17(12), 10259-10264.

Pacoret, C., \& Régnier, S. (2013). Invited article: A review of haptic optical tweezers for an interactive microworld exploration. Review of Scientific Instruments, 84(8).

Persson, P., Cooper, M., Tibell, L., Ainsworth, S., Ynnerman, A., \& Jonsson, B.-H. (2007). Designing and evaluating a haptic system for biomolecular education. IEEE Virtual Reality Conference, (pp. 171-178).

Pillarisetti, A., Anjum, W., Desai, J., Friedman, G., \& Brooks, A. (2005). Force feedback interface for cell injection. World Haptics Conference, (pp. 391-400).

Pillarisetti, A., Pekarev, M., Brooks, A. D., \& Desai, J. P. (2007). Evaluating the effect of force feedback in cell injection. IEEE Transactions on Automation Science and Engineering, 4(3), 322-331.

Podolefsky, N. S., \& Finkelstein, N. D. (2006). Use of analogy in learning physics: The role of representations. Physical Review Special Topics - Physics Education Research, 2(2), 020101.

Rodrigo, P., Kelemen, L., Palima, D., Alonzo, C., Ormos, P., \& Glückstad, J. (2009). Optical microassembly platform for constructing reconfigurable microenvironments for biomedical studies. Optics Express, 17(8), 6578-6583. 
Ruh, D., B., T., \& Rohrbach, A. (2011). Fast parallel interferometric 3D tracking of numerous optically trapped particles and their hydrodynamic interaction. Optics Express, 19(22), 21627-21642.

Sankaranarayanan, G., Weghorst, S., Sanner, M., Gillet, A., \& Olson, A. (2003). Role of haptics in teaching structural molecular biology. Symposium on Haptic Interfaces for Virtual Environment and Teleoperator Systems, (pp. 363-366).

Schmid, A., Yechangunja, R., Thalhammer, S., \& Srinivasan, M. A. (2012). Human-operated 3D micro-manipulator with haptic feedback. IEEE Haptics Symposium, (pp. 517-522).

Shirinov, A., Kamenik, J., \& Fatikow, S. (2004). Haptic interface for a nanohandling robot. Assembly Automation, 24(1), 78-87.

Sitti, M., \& Hashimoto, H. (1998). Macro to nano tele-manipulation through nanoelectromechanical systems. IEEE Industrial Electronics Society, (pp. 98-103).

Sitti, M., \& Hashimoto, H. (1998). Tele-nanorobotics using atomic force microscope. IEEE/RSJ International Conference on Intelligent Robots and Systems, (pp. 17391746).

Sitti, M., \& Hashimoto, H. (2003). Teleoperated touch feedback from the surfaces at the nanoscale: modeling and experiments. IEEE/ASME Transactions on Mechatronics, 8(2), 287-298.

Sourina, O., Torres, J., \& Wang, J. (2008). Visual haptic-based biomolecular docking. International Conference on Cyberworlds, (pp. 240-247).

Steinfeld, A., Fong, T., Kaber, D., Lewis, M., Scholtz, J., Schultz, A., \& Goodrich, M. (2006). Common metrics for human-robot interaction. ACM SIGCHI/SIGART Conference on Human-Robot Interaction, (pp. 33-40).

Subasi, E., \& Basdogan, C. (2008). A new haptic interaction and visualization approach for rigid molecular docking in virtual environments. Presence: Teleoperators and Virtual Environments, 17(1), 73-90.

Sugiura, T., Nakao, M., Sato, T., \& Minato, K. (2008). Nanomanipulation and nanotechnology for future diagnostics. Studies in Health Technology and Informatics, $134,135-142$.

Tamadazte, B., Le Fort-Piat, N., \& Marchand, E. (2011). A direct visual servoing scheme for automatic nanopositioning. IEEE-ASME Transactions on Mechatronics, 17(4), 1-10.

Taylor II, R. (1997). Programming force feedback devices in computer graphics systems. Course notes for "Programming Virtual Worlds", Special Interest Group on GRAPHics and Interactive Techniques (SIGGRAPH). 
Taylor II, R., Chen, J., Okimoto, S., Llopis-Artime, N., Chi, V. L., Brooks Jr., F. P., . . . Superfine, R. (1997). Pearls found on the way to the ideal interface for scanned-probe microscopes. Conference on Visualization, (pp. 467-470).

van West, E., Yamamoto, A., \& Higuchi, T. (2007). The concept of "Haptic Tweezer", a noncontact object handling system. Mechatronics, 17(7), 345-356.

Varol, A., Gunev, I., \& Basdogan, C. (2006). A virtual reality toolkit for path planning and manipulation at nano-scale. Symposium on Haptic Interfaces for Virtual Environment and Teleoperator Systems, (pp. 485-489).

Venture, G., Haliyo, D. S., Micaelli, A., \& Régnier, S. (2006). Force-feedback micromanipulation with inconditionnally stable coupling. International Journal of Micromechatronics, special issue on Micro-handling, 3(3), 307-327.

Vijayasai, A. P., Sivakumar, G., Mulsow, M., Lacouture, S., Holness, A., \& Dallas, T. E. (2010). Haptic controlled three-axis MEMS gripper system. Review of Scientific Instruments, 81, 105114.

Vogl, W., Ma, B. K.-L., \& Sitti, M. (2006). Augmented reality user interface for an atomic force microscope-based nanorobotic system. IEEE Transactions on Nanotechnology, 5(4), 397-406.

Wollacott, A. M., \& Merz Jr., K. M. (2007). Haptic applications for molecular structure manipulation. Journal of Molecular Graphics and Modelling, 25(6), 801-805.

Xie, H., \& Régnier, S. (2009). Three-dimensional automated micromanipulation using a nanotip gripper with multifeedback. Journal of Micromechanics and Microengineering, 19.

Xie, H. \& Régnier, S. (2011). Development of a Flexible Robotic System for Multiscale Applications of Micro/Nanoscale Manipulation and Assembly. IEEE/ASME Transaction on Mechatronics, 16(2), 266-276.

Zhang, H., \& Liu, K.-K. (2008). Optical tweezers for single cells. Journal of the Royal Society Interface, 5(24), 671-690.

Zhang, J., Li, G., \& Xi, N. (2005). Modeling and control of active end effector for the AFM based nano robotic manipulators. IEEE International Conference on Robotics and Automation, (pp. 163-168). 